\title{
A generic mathematical model to optimise strategic and tactical decisions in biomass-based supply chains (OPTIMASS)
}

\author{
Annelies De Meyer ${ }^{\mathrm{a}}$, Dirk Cattrysse ${ }^{\mathrm{b}}$, Jos Van Orshoven $^{\mathrm{a}}$ \\ ${ }^{a}$ Department of Earth and Environmental Sciences, Division Forest, Nature and Landscape, KU Leuven, Celestijnenlaan 200E, 3001 Leuven, \\ Belgium \\ ${ }^{b}$ Department of Mechanical Engineering, Centre for Industrial Management / Traffic E Infrastructure, KU Leuven, Celestijnenlaan $300 \mathrm{~A}, 3001$ \\ Leuven, Belgium
}

\begin{abstract}
High logistics and handling costs prevent the bioenergy industry from making a greater contribution to the present energy market. Therefore, a mathematical model, OPTIMASS, is presented to optimise strategic (e.g. facility location and type) and tactical (e.g. allocation) decisions in all kinds of biomass-based supply chains. In addition to existing models, OPTIMASS evaluates changes in biomass characteristics due to handling operations which is needed to meet the requirements set to biomass products delivered at a conversion facility. Also, OPTIMASS considers the reinjection of by-products from conversion facilities which can play a decisive role in the determination of a sustainable supply chain.

The scenario analysis illustrates the functionalities of OPTIMASS in the optimisation of an existing supply chain, the definition of the optimal location of new conversion facilities and the definition of the optimal configuration of a supply chain. OPTIMASS, as a deterministic model, does not consider variability related to e.g. seasonal changes which can be a major obstacle. However, a thorough sensitivity analysis of influencing factors must give insight in the induced changes in the supply chain. The sensitivity analysis in this paper investigates the influence of uncertainty in biomass production, energy demand and of changes in transport distance. The analysis demonstrate that OPTIMASS can be used as an inspiring tool to investigate the possible effects of governmental decisions, of considering new biomass material, new facilities, of technology changes, etc. The coupling with GIS allows characterisation and visualisation of problems in advance and visualisation of results in an interpretative way.
\end{abstract}

Keywords: OR in energy, Strategic planning, Supply chain management, Linear programming

\section{Introduction}

Forecasts indicate that by 2050 the world energy consumption will reach 812 EJ (International Energy Administration, 2011). This implies an increase by $53 \%$ in comparison with the energy consumption of $532 \mathrm{EJ}$ in 2008 (International Energy Administration, 2011). Combined with the finiteness of fossil fuels and the consequences of greenhouse emissions, this increase in energy consumption triggers the investigation of diverse alternative and renewable energy sources. Biomass is considered as an attractive source of energy (Mafakheri and Nasiri, 2014) because it is abundantly present and it can be stored to generate energy on demand (Rentizelas et al., 2009; Mafakheri and Nasiri, 2014). Despite these advantages, biomass is a source of energy that is generally underutilised. The obstacles that have prevented the bioenergy sector from making a greater contribution to the present energy market are mainly related to uncertainties related to weather variability, policy and market conditions (Shabani et al., 1998) and to barriers induced by high costs for transport and handling of biomass materials in a complex supply chain (Gold and Seuring, 2011; Shabani et al., 1998). These costs cannot be avoided since these operations are indispensable to deal with the typical characteristics of biomass (e.g. spatial fragmentation, seasonal availability, high moisture content, low heating value and low bulk density). It is clear that the development of a strong and sustainable bioenergy industry depends upon the extent to which these obstacles can be overcome considering the interrelated decisions within the supply chain, the complex hierarchy in the decision making and the role of each actor within the chain (Awudu and Zhang, 2012; Iakovou et al., 2010; Shabani et al., 1998; Sharma et al., 2013). 


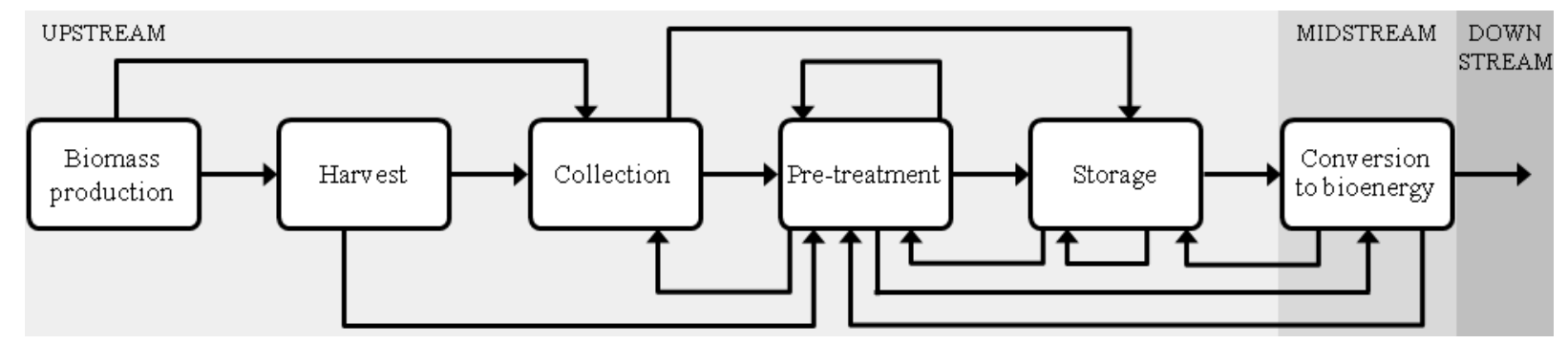

Figure 1: Conceptual model representing the sequence of operations in the biomass supply chain $(\mathrm{a}$ box $=$ operation; arrow $=$ material flow) (De Meyer et al., 2013a)

Finding the best possible supply chain configuration is part of supply chain management (Melo et al., 2009) in which the planning of all activities involved in sourcing and procurement, conversion and logistics are considered (Council of Supply Chain Management Professionals, 2012). The development of the discipline "supply chain management" started independently of operational research (Melo et al., 2009). Gradually, standard models to solve uncapacitated and capacitated facility location problems have been extended to meet more realistic facility location settings and to include supply chain management decisions in addition to the definition of the optimal facility location (Melo et al., 2009). For example, the inclusion of multiple facility layers and capacities (Klose and Drexl, 2005), time changing parameters (Melo et al., 2006), uncertainties (Snyder, 2006), hierarchy levels between facilities (Sahin and Sural, 2007), etc. From these review papers it is clear that a variety of extended optimisation models has been developed which can been applied to optimise supply chains in various sectors and industries (e.g. automotive industry, forestry, telecommunication, food sector, retail, military) (Melo et al., 2009; Rahmaniani and Ghaderi, 2013).

An increasing number of research papers report the combination of supply chain management and optimisation methods in the field of bioenergy systems, as reviewed in a.o. Shabani et al. (1998); Sharma et al. (2013); De Meyer et al. (2014); Mafakheri and Nasiri (2014). Usually, these optimisation models divide the bioenergy supply chain into three major segments according to the products and operations observed (An et al., 2011) (Figure 1). The upstream segment covers the operations from biomass production to the delivery to the conversion facility in which the conversion process itself is considered as a black box with input of biomass and output of bioenergy and by-products. The midstream segment considers the conversion process itself. The downstream segment encompasses the storage of bioenergy and its distribution to customers. Models have been published to optimise the downstream segment of the bioenergy supply chain, e.g. the production and distribution of bioenergy (e.g. Uhlemair et al. (2014)) or concentrate on optimal plant setups (i.e. midstream segment) (e.g. Lauven (2014)). However, most obstacles hampering the development of a reliable bioenergy market are associated with the characteristics of biomass products. Therefore, a variety of models relate to the optimisation of the upstream supply chain (Shabani et al., 1998; Sharma et al., 2013; De Meyer et al., 2014; Mafakheri and Nasiri, 2014). Usually, these models are developed to optimise a specific supply chain based on a certain biomass type or a certain situation. In addition, the models only address a specific part of the supply chain, usually limited to biomass supply, collection and conversion (Sharma et al., 2013; De Meyer et al., 2014; Mafakheri and Nasiri, 2014). Since sustainability of supply chains has emerged as a concern to address the potential of supply chains to take into account 'the long-term risks associated with resource depletion, fluctuations in energy costs, product liabilities, and pollution and waste management' (Shrivasta, 2007), the optimisation models should not only consider energy related impacts but also economic, environmental and social impacts in the decision making process (Shabani et al., 1998). However, most models are developed to minimise the overall cost or to maximise the revenue (Sharma et al., 2013; De Meyer et al., 2014). As mentioned previously, uncertainties in the supply chain play a decisive role. Unfortunately, most models are deterministic ignoring the uncertainty in the supply chain (Shabani et al., 1998).

To develop an optimisation tool which is of interest for different stakeholders, there is a need for an integrated, holistic approach giving equal emphasis to all operations in the entire supply chain (Baños et al., 2011; De Meyer et al., 2014). The generic mathematical model, called OPTIMASS, presented in this paper (Section 2) is meant to optimise the strategic and tactical decisions in all kinds of upstream bioenergy supply chains based on the maximal net energy output, maximal revenue, minimal global warming potential or maximal job input. However, to improve the 
readability, this paper focuses on the maximisation of the net energy output. So, the mathematical model supports the strategic, long term decisions pertaining to the design of the biomass supply chain such as sourcing and procurement of biomass, the allocation of biomass between facilities and the location, capacity and technology of intermediate storage and conversion facilities. If the design of the supply network (i.e. strategic decision) is fixed, OPTIMASS can be used to optimise tactical decisions for one representative period concentrating on logistics planning (e.g. allocation of biomass, selection of collection, storage, pre-treatment and transportation methods and inventory planning).

The novelty of the model as presented in this paper is fourfold. First, OPTIMASS is applicable to all kinds of biomass-based supply chains. To improve the usability and adaptability by different stakeholders, the mathematical model is connected to a generic and flexible relational database covering the parameters it requires. With the connection to a GIS it allows characterisation and visualisation of the problem and the result and/or computation of spatial parameters involved in the problem. Secondly, OPTIMASS takes into account changes in biomass characteristics due to handling and pre-treatment operations, typical to biomass-based supply chains. Therefore, transformation coefficients are created that define the transition from one product type to another due to handling operations. This implies that transformation coefficients are linked to operation types defining the material transformation due to that operation. This approach is similar to the approach used in the specific multi-period MILP model of Walther et al. (2012) in which the design of production networks for second generation synthetic bio-diesel is addressed. However, in their MILP model, the transformation coefficients are linked to the product to be created in stead of the operation type. Thirdly, the model considers the re-injection of by-products from the conversion process in the biomass-based supply chain. To the best of our knowledge, this has already been part of the optimisation of supply chains in other industries (e.g. Fröhling et al. (2010) in the metallurgical industry), but not yet in the bioenergy sector. Finally, OPTIMASS, as presented in this paper, can be applied to optimise biomass-based supply chains according to one out of the four objectives. To move towards the development of sustainable biomass-based supply chains, this MILP model can be seen as the base for multi-objective optimisation. This final topic is part of a paper prepared by the authors in which the mathematical model is combined with compromise programming to define the optimal supply chain based on a trade-off between different objectives (De Meyer et al., 2015).

After giving insight in the developed mathematical model (Section 2), this paper illustrates the functionalities and possibilities of the model by the application of OPTIMASS to a bioenergy supply chain of biomass derived from low input high diversity (LIHD) biomass systems to anaerobic digesters and composting facilities in the Limburg province (Belgium) (Section 5). Since OPTIMASS is a deterministic model, a sensitivity analysis is performed to give insight in the influences of uncertainty in biomass production and energy demand and the effect of the transport distance (Section 6). These analyses result in an evaluation of the behaviour of OPTIMASS (Section 7) and the definition of opportunities for its further elaboration (Section 8).

\section{Mathematical model}

\subsection{Approach}

OPTIMASS is developed to optimise strategic decisions within all kinds of biomass-based supply chains. These decisions are long term, usually investment intensive pertaining to the design of the biomass supply chain such as sourcing and procurement of biomass, the allocation of biomass between facilities and the location, capacity and technology of intermediate storage and conversion facilities (D'Amours et al., 2008; Iakovou et al., 2010; Awudu and Zhang, 2012; De Meyer et al., 2014). If the design of the supply chain (i.e. strategic decision) is fixed, OPTIMASS can be used to optimise tactical decisions for one representative time period, concentrating on logistics planning (e.g. allocation of biomass, selection of collection, storage,pre-treatment and transportation methods and inventory planning). To allow the application to different biomass supply chains, an integrated, holistic approach is required. This implies that the model includes the six key operations and the allowed sequences (Figure 1) in combination with the possible flows within the supply chain (Figure 2) and keeping track of the changes in biomass characteristics due to these operations.

To meet these objectives, the optimisation problem is approached as a multi-stage capacitated facility location planning problem (Melkote and Daskin, 2001) in which at each facility the characteristics of the biomass product can change due to handling operations. This translates into a deterministic, static, multi-echelon, multi-product mixed integer linear programming model (MILP) (Klose and Drexl, 2005) that describes the material flow and decision 


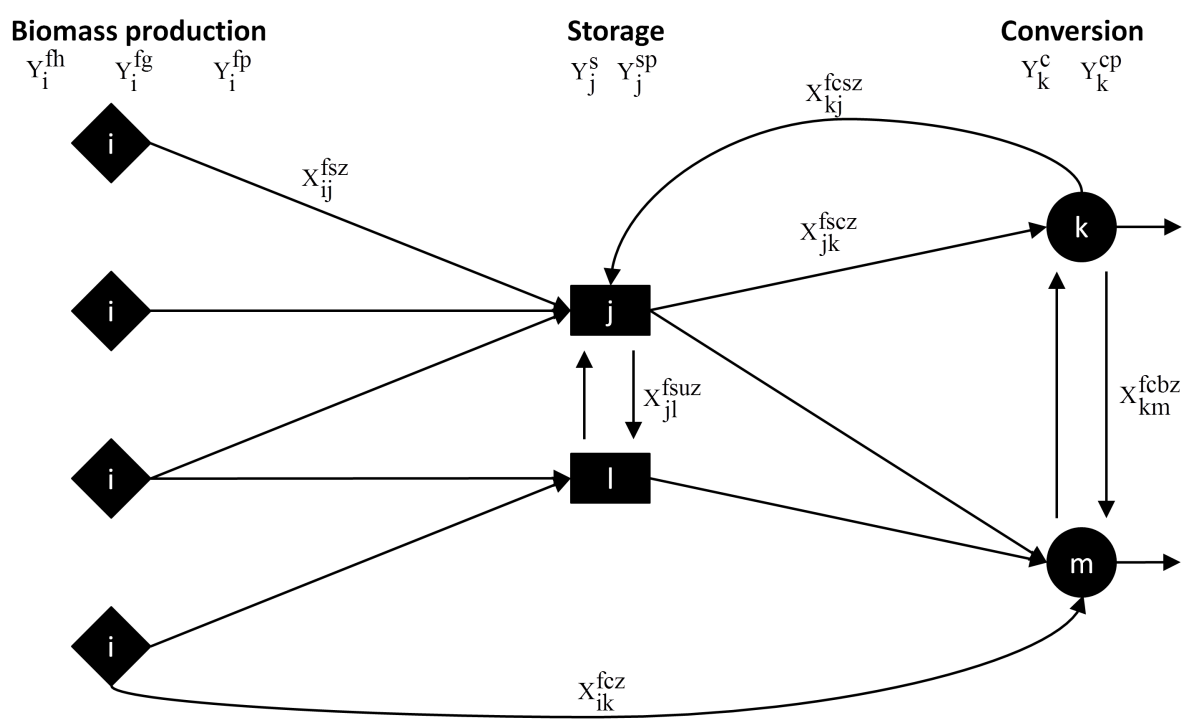

Figure 2: Generic view on the considered biomass-based supply network (Explanation of symbols in Appendix A (Supplementary material))

stages presented in figures 2 and 3. Figure 2 depicts a generic view on the considered biomass-based supply chain network including the different locations (i.e. biomass production site $\mathrm{i}$, storage sites $\mathrm{j}$ and $\mathrm{l}$, conversion sites $\mathrm{k}$ and $\mathrm{m})$ and the possible material flows. In this model, integer variables (Y) determine the optimal harvest and collection type at biomass production sites $\left(Y_{i}^{f h}, Y_{i}^{f g}\right)$ and the optimal location, technology and capacity of storage $\left(Y_{j}^{s}\right)$, pretreatment $\left(Y_{i}^{f p}, Y_{j}^{s p}, Y_{k}^{c p}\right)$ and conversion facilities $\left(Y_{k}^{c}\right.$ ). Continuous variables (X) (arrows in figure 2) define the allocated quantities of feedstock and intermediates from biomass production sites to operation facilities $\left(X_{i j}^{f s z}, X_{i k}^{f c z}\right)$ and of feedstock, intermediates and by-products between operation facilities $\left(X_{j k}^{f s c z}, X_{j l}^{f s u z}, X_{k m}^{f c b z}, X_{k j}^{f c s z}\right)$.

On each site, handling operations (i.e. harvest, pre-treatment or conversion) can occur which changes the biomass characteristics of the biomass. To visualise the material flow within the sites through the handling operations, figure 2 has been extended to figure 3 . The grey shaded areas resemble the possible locations and decisions concerning material flows are represented by the arrows. To consider changes in biomass characteristics due to harvest and pre-treatment operations, additional continuous variables are introduced to enforce the mass balance before and after harvesting $(\mathrm{H})$ and pre-treatment $(\mathrm{P})$ operations. These mass balance requirements are represented by the small circles in figure 3. Furthermore, continuous variables $(\mathrm{R})$ are included to determine the by-product produced during the conversion process. This by-product can be re-used in the supply chain $\left(X_{k j}^{f c s z}\right.$ and $\left.X_{k m}^{f c b z}\right)$ or can leave the chain $\left(R_{k o u t}^{c f}\right)$. Finally, the continuous variable $C_{k}^{e c}$ is introduced to allow the use of a certain "extra" biomass product in the conversion process. This is necessary when e.g. the stakeholder is not interested in the optimisation of the delivery of a certain biomass product, but the biomass product is required in the conversion process. OPTIMASS determines the optimal quantity of this extra product used in each conversion facility considering a certain energy input related to the use of the extra product, the maximum available quantity and several requirements in the conversion facility.

\subsection{Objective}

OPTIMASS can define the supply chain of a biomass-based system resulting in the maximal profit, the maximal net energy output or the minimal global warming potential. Optimisation of the supply chain based on a trade-off between these conflicting objectives is the subject of ongoing research. Since all objectives are constructed in a similar way, this paper focuses on the description of the energetic objective. The maximal net energy output $E_{\text {tot }}(1)$ is determined by the annual quantity of bioenergy produced by the conversion facilities in the chain $\left(E_{\text {out }}\right)(2)$ minus the energy needed for the handling operations $\left(E_{i n}^{h}, E_{i n}^{g}, E_{i n}^{p}\right)((3)-(5))$, the energy needed for the transport $\left(E_{i n}^{t r}\right)(6)$ and the energy needed for the management or usage of the equipment and facilities $\left(E_{i n}^{\text {start }}\right)(7)$. The terms considering the transport and handling operations determine the optimal flow of biomass throughout the supply chain as presented in 


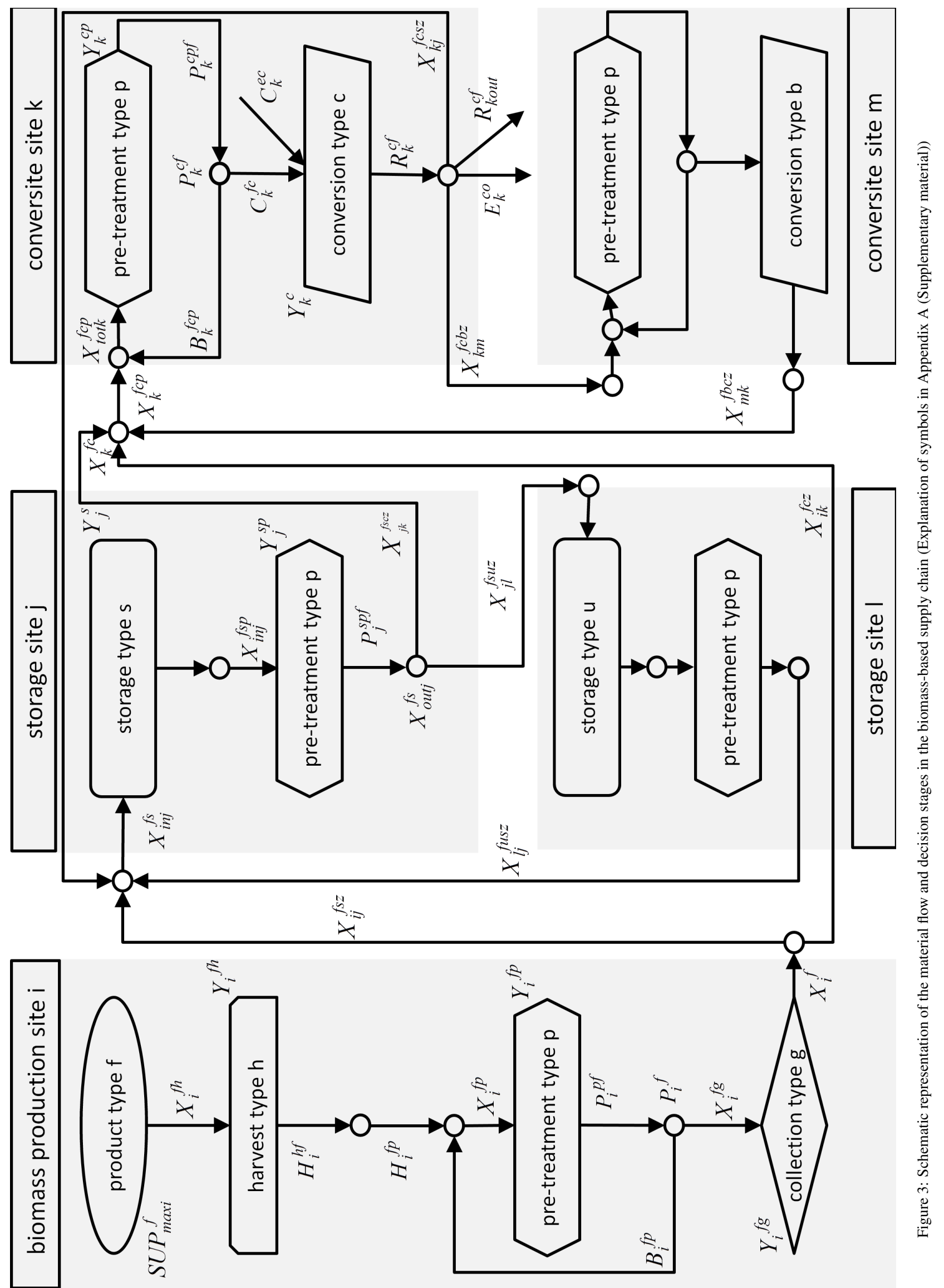


figure 1 and figure 3. The terms defining the handling operations include the energy needed to harvest the biomass at the production site (3), the energy needed to collect the harvested biomass, whether or not pre-treated, (4) and the energy needed to pre-treat the feedstock, intermediates and by-products on the biomass production site, storage site or conversion site (5). The transport term (6) considers the energy for transport as well as the energy needed to load and unload the transport vehicles. The management term determines the optimal harvest and collection technology at biomass production sites and the optimal location, technology and capacity of storage, pre-treatment and conversion facilities. The management term co-determines the optimal operation type to be applied by taking into account the energy needed to drive harvesting and collection equipment between the road and the biomass production site, to run the opened operation facilities, and to use the extra products in the supply chain. An explanation of each symbol is available in Appendix A (Supplementary material).

$$
\begin{aligned}
& E_{\text {tot }}=E_{\text {out }}-\left(E_{\text {in }}^{h}+E_{\text {in }}^{g}+E_{\text {in }}^{p}+E_{\text {in }}^{\text {tr }}+E_{\text {in }}^{\text {start }}\right) \\
& E_{\text {out }}=\sum_{k \in K} \sum_{c \in C} \sum_{o \in O} E_{k}^{c o} \\
& E_{\text {in }}^{h}=\sum_{i \in I} \sum_{f \in F} \sum_{h \in H}\left(\frac{E^{h} X_{i}^{f h}}{v^{h} \rho^{f}}\right) \\
& E_{i n}^{g}=\sum_{i \in I} \sum_{f \in F} \sum_{g \in G}\left(E^{g} X_{i}^{f g}\right) \\
& E_{i n}^{p}=\sum_{i \in I} \sum_{f \in F} \sum_{p \in P}\left(E^{p} X_{i}^{f p}\right)+\sum_{f \in F} \sum_{j \in J} \sum_{s \in S} \sum_{p \in P}\left(E^{p} X_{i n j}^{f s p}\right)+\sum_{f \in F} \sum_{k \in K} \sum_{c \in C} \sum_{p \in P}\left(E^{p} X_{k}^{f c p}\right) \\
& E_{i n}^{t r}=\sum_{i \in I} \sum_{f \in F} \sum_{j, l \in J} \sum_{s, u \in S} \sum_{k, m \in K} \sum_{c, b \in C} \sum_{z \in Z}\left[\left(\frac{d_{i j}^{z}}{\rho^{f}} X_{i j}^{f s z}+\frac{d_{i k}^{z}}{\rho^{f}} X_{i k}^{f c z}+\frac{d_{j k}^{z}}{\rho^{f}} X_{j k}^{f s c z}+\frac{d_{j l}^{z}}{\rho^{f}} X_{j l}^{f s u z}+\frac{d_{k j}^{z}}{\rho^{f}} X_{k j}^{f c s z}+\frac{d_{k m}^{z}}{\rho^{f}} X_{k m}^{f c b z}\right) E_{t r}^{z}+\right. \\
& \left.\left(X_{i j}^{f s z}+X_{i k}^{f c z}+X_{j k}^{f s c z}+X_{j l}^{f s u z}+X_{k j}^{f c s z}+X_{k m}^{f c b z}\right)\left(E_{\text {load }}^{z}+E_{\text {unload }}^{z}\right)\right] \\
& E_{\text {in }}^{\text {start }}=\sum_{i \in I} \sum_{f \in F} \sum_{h \in H}\left(2 d_{i} E_{\text {man }}^{h} Y_{i}^{f h}\right)+\sum_{i \in I} \sum_{f \in F} \sum_{g \in G}\left(2 d_{i} E_{\text {man }}^{g} Y_{i}^{f g}\right)+\sum_{i \in I} \sum_{f \in F} \sum_{p \in P}\left(E_{\text {run }}^{p} Y_{i}^{f p}\right)+ \\
& \sum_{j \in J} \sum_{s \in S}\left(s C A P_{\max j}^{s} E_{\text {run }}^{s} Y_{j}^{s}\right)+\sum_{k \in K} \sum_{c \in C}\left(E_{\text {run }}^{c} Y_{k}^{c}\right)+\sum_{e \in E} \sum_{k \in K} \sum_{c \in C}\left(E_{u s e}^{e} C_{k}^{e c}\right)
\end{aligned}
$$

\subsection{Constraints}

Three groups of constraints are introduced to regulate the material flow as described in figure 3:

- One group of constraints imposes physical and regulatory limitations on the combinations between biomass products and operations and operations mutually and on the allowed operations at the biomass production sites (i), storage sites $(\mathrm{j}, \mathrm{l})$ and conversion sites $(\mathrm{k}, \mathrm{m})$ (Section 2.3.1).

- A second group of constraints ensures mass balance in the material flow in operations, between operations at a location and between locations on the available (multi-modal) transportation network (2.3.2).

- A third group of constraints ensures that the energy demand and the demand for a certain by-product are met (Section 2.3.3).

To secure the readability of this paper, only these constraints presenting the general structure of the model are included as well as the constraints to close the research gaps identified in the introduction. 


\subsubsection{Operation constraints}

The six key operations in the biomass supply chain are required to deal with the typical characteristics of biomass (e.g. spatial fragmentation, seasonal and weather related variability, high moisture content, low energy content, low bulk density) (Gold and Seuring, 2011; Rentizelas et al., 2009; Wee et al., 2012; Shabani et al., 1998). Because upstream decisions affect the later operations in the chain, and the choice of technology and location of the conversion facility determines the type and sequence of all previous operations (Iakovou et al., 2010), constraints are added to regulate the limitations on the combinations between biomass products and operations and operations mutually and on the allowed operations at the biomass production sites (i), storage sites ( $\mathrm{j}, \mathrm{l})$ and conversion sites $(\mathrm{k}, \mathrm{m})$. These constraints are linked to the boxes in figure 3 presenting the possible operations at the biomass production sites, storage sites and conversion sites.

To describe the allowed combinations between biomass products and operations and between operations, binary parameters (0-1) are introduced into the constraints. For example, constraint (8) states that a product of type f can only be supplied to pre-treatment type $\mathrm{p}$ at conversion facility of type $\mathrm{c}$ at location $\mathrm{k}\left(X_{k}^{f c p}\right)$ if the combination between product type $\mathrm{f}$ and pre-treatment type $\mathrm{p}$ exists $\left(L^{f p}=1\right)$ and pre-treatment type $\mathrm{p}$ is allowed at a conversion facility of type $\mathrm{c}\left(L^{c p}=1\right)$.

$$
X_{k}^{f c p} \leq L^{f p} L^{c p} p C a p_{\max } \quad \forall f \in F, k \in K, c \in C, p \in P
$$

Each of the operations is subjected to capacity restrictions. Therefore, restrictions are introduced to consider the limiting capacity of equipment. For example, constraint (9) determines that not more biomass can be harvested at location $i$ as the maximum capacity of the harvesting equipment used. At storage sites the capacity is not only limited by the storage type, but also by the site itself (constraint (10): $s C A P_{j \max }^{s}$ ).

$$
\begin{aligned}
& \frac{X_{i}^{f h}}{\rho^{f}} \leq h C A P_{\max }^{h} Y_{i}^{f h} \quad \forall i \in I, f \in F, h \in H \\
& \sum_{f \in F}\left(\frac{X_{\text {in } j}^{f s}}{\rho^{f}}\right) \leq s C A P_{j \max }^{s} Y_{j}^{s} \quad \forall j \in J, s \in S
\end{aligned}
$$

At the conversion facility, biomass is also subjected to minimum and maximum requirements for particle size and moisture content in addition to the capacity constraints (e.g. constraint (11)). To allow a mixture of different types of biomass in the conversion process, constraints are added regulating the minimum required and maximum allowed fraction of a certain biomass type within the conversion process (e.g. constraint (12)). Similar to constraint 12 , constraints are added to regulate the minimum required and maximum allowed quantity of extra products in the conversion process.

$$
\begin{gathered}
P S^{f} C_{k}^{f c} \leq P S_{\max }^{c} C_{k}^{f c} \quad \forall f \in F, k \in K, c \in C \\
C_{k}^{f c} \geq M_{\text {min }}^{f c} \sum_{f \in F} C_{f k}^{c} \quad \forall f \in F, k \in K, c \in C
\end{gathered}
$$

During harvest and pre-treatment, the characteristics of the biomass change. For example, grass harvesting with different mowers results in different particle sizes and a drying operation obviously results in a lower moisture content than the one of the feedstock. To define the transformation from one biomass type $\mathrm{f}$ into another biomass type $\mathrm{r}$ during a harvesting (h) or pre-treatment (p) operation, the transformation coefficients $\gamma^{f h r}$ and $\gamma^{f p r}$ are introduced in constraint (13) and constraint (14) (cfr. (Walther et al., 2012)). A similar formulation is used to define the type of by-product produced during the conversion process (constraint (15)) in which $\gamma^{f c r}$ defines the transformation from the supplies biomass products and $\gamma^{e c r}$ the transformation from the extra products. The transformation coefficients range between 0 and 1 .

$$
H_{i}^{h r}=\sum_{f \in F}\left(\gamma^{f h r} X_{i}^{f h}\right) \quad \forall i \in I, r \in F, h \in H
$$




$$
\begin{gathered}
P_{i}^{p r}=\sum_{f \in F}\left(\gamma^{f p r}\left(1-\Delta^{p}\right) X_{i}^{f p}\right) \quad \forall i \in I, r \in F, p \in P \\
R_{k}^{c r}=\sum_{f \in F}\left(\gamma^{f c r} C_{k}^{f c}\right)+\sum_{e \in E}\left(\gamma^{e c r} C_{k}^{e c}\right) \quad \forall r \in F, k \in K, c \in C
\end{gathered}
$$

Constraint (14) considers the biomass loss during pre-treatment operation $\mathrm{p}\left(\Delta^{p}\right)$. In addition, the MILP considers biomass loss during collection (g) and storage (s) by incorporating constraints (16) and (17).

$$
\begin{gathered}
X_{i}^{f}=\sum_{g \in G}\left(\left(1-\Delta^{g}\right) X_{i}^{f g}\right) \quad \forall i \in I, f \in F \\
X_{\text {out } j}^{f s}=\sum_{p \in P}\left(\left(1-\Delta^{s}\right) P_{j}^{s p f}\right) \quad \forall f \in F, j \in J, s \in S
\end{gathered}
$$

\subsubsection{Mass balance constraints}

To ensure the material flow through the supply chain, mass balance constraints are added to regulate the flow of biomass in operations, between operations at a location and between locations on the available (multi-modal) transportation network. To start, constraint (18) limits the quantity of biomass that can be harvested at the biomass production site $\left(X_{i}^{f h}\right)$ and therefore also the quantity of biomass that can enter the chain.

$$
S u p_{\max i}^{f} \geq \sum_{h \in H} X_{i}^{f h} \quad \forall i \in I, f \in F
$$

Constraints such as constraint (19) are included to ensure the material flow between locations. For example, constraint (19) determines that the quantity of a biomass type f entering the storage facility of type $s$ at site $j$ equals the quantities of that biomass type $\mathrm{f}$ transported from biomass production sites (i), storage sites (l) or conversion sites (k) to that site.

$$
X_{i n j}^{f s}=\sum_{i \in I} \sum_{z \in Z} X_{i j}^{f s z}+\sum_{l, u \in L} \sum_{z \in Z} X_{l j}^{f u s z}+\sum_{k \in K} \sum_{c \in C} \sum_{z \in Z} X_{k j}^{f c s z} \quad \forall f \in F, j \in J, s \in S
$$

To guarantee the possibility to re-inject by-products, such as digestate, into a subsequent conversion process with or without previous pre-treatment and/or storage, constraint (20) is added to send the by-product back into the supply chain. This constraint also covers a certain quantity of by-product that leaves the chain $\left(R_{\text {kout }}^{c f}\right)$.

$$
R_{k}^{c f}=\sum_{m \in K} \sum_{b \in C} \sum_{z \in Z} X_{k m}^{f c b z}+\sum_{j \in J} \sum_{s \in S} \sum_{z \in Z} X_{k j}^{f c s z}+R_{k o u t}^{c f} \quad \forall f \in F, k \in K, c \in C
$$

To regulate the material flow between operations at the same site, constraints are added to balance the quantity of biomass type $\mathrm{f}$ leaving an operation with the quantity of that biomass type entering a subsequent operation. For example, constraint (21) determines that the total amount of biomass type $f$ harvested by the different harvesting types (h) equals the total amount of biomass type $\mathrm{f}$ entering the different pre-treatments $(\mathrm{p})$.

$$
\sum_{h \in H} H_{i}^{h f}=\sum_{p \in P} H_{i}^{f p} \quad \forall i \in I, f \in F
$$

Figure 1 and figure 3 indicate that a sequence of pre-treatment operations can occur at the biomass production site before collection. Therefore, the variable $B_{i}^{f p}$ is added to ensure mass balance at the biomass production site. Constraint (23) defines that a certain intermediate of type $f$ can enter a subsequent pre-treatment type $p$ or is collected by collection type $\mathrm{g}$ while constraint (22) considers the reception of that intermediate of type for subsequent pretreatment in type $\mathrm{p}$. A similar set of constraints is added to cover the pre-treatment loop at the conversion site before conversion (c) takes place. This set of constraints is not needed at the storage site because no other operation occurs 
than pre-treatment. This implies that the pre-treatment loop is covered in the mass balance constraints regulating the material flow between 2 storage sites $\left(X_{j l}^{f s u}\right)$ in which the storage sites are at the same location.

These constraints are not necessary at the storage sites because here the model assumes a transport operation between storage facilities at the same site.

$$
\begin{aligned}
& X_{i}^{f p}=H_{i}^{f p}+B_{i}^{f p} \quad \forall i \in I, f \in F, p \in P \\
& P_{i}^{f}=\sum_{g \in G} X_{i}^{f g}+\sum_{p \in P} B_{i}^{f p} \quad \forall i \in I, f \in F
\end{aligned}
$$

\subsubsection{Demand constraints}

The final group of constraints considers the total energy demand (constraints (24)-(25)) and the total demand for a certain by-product in the supply chain (constraint (26)). The demand constraint (24) ensures that the total demand for each bioenergy type (e.g. heat, electricity) is met by the conversion facilities in the optimised supply chain. However, the production of an energy surplus is allowed (constraint (25)).

$$
\begin{gathered}
E_{\text {surplus }}^{o}=\sum_{k \in K} \sum_{c \in C}\left(E_{k}^{c o}\right)-D^{o} \quad \forall o \in O \\
E_{\text {surplus }}^{o} \leq Q^{o} D^{o} \quad \forall o \in O \\
\sum_{k \in K} \sum_{c \in C} R_{k \text { out }}^{c f} \geq R_{\text {demand }}^{f} \forall f \in F
\end{gathered}
$$

\section{System implementation}

The presented MILP model is part of a conceptual decision support system (DSS) in which three modules are at stake: (1) a database module, (2) a query module and (3) the MILP-based optimisation module (De Meyer et al., 2013b). The database (developed in PostgreSQL with PostGIS extension (PostgreSQL GDB, 2011) covers the parameters required in the optimisation module (De Meyer et al., 2012). To be able to describe all (or most) biomass supply chains and to enable easy addition, deletion or change of types, attributes and attribute values, the data model is divided into a non-spatial and a spatial part (De Meyer et al., 2012). The non-spatial component is the core of the data model and encompasses the data covering the product types and the techniques to handle and transport products with their attributes on the one hand and their relationships and possible sequences on the other hand. The spatial component contains the geospatial definition of the (multi-modal) transportation network and the geospatial coordinates of the (potential) biomass production sites, storage facilities and conversion facilities. It is linked to the query module (developed in ArcGIS 10.2 (ESRI, 2013) enabling users to organise and pre-process the initial spatial information and to visualise and post-process the optimisation results. Furthermore, the query module is used to determine the shortest distance between all locations for each transport type by applying the Network Analyst extension of ArcGIS 10.2 (ESRI, 2013). The optimisation module encompasses the presented MILP model developed in LINGO 14 (LINDO Systems Inc., 2013).

\section{Use case: LIHD biomass supply chain}

By 2020, use of primary bioenergy in Europe is forecasted to increase 2.5 times in comparison to the level in 2011 (from 85 Mtoe to 215 Mtoe) (Bjerg et al., 2011). To meet the corresponding future biomass demand, other biomass sources than hitherto applied need to be addressed (Bjerg et al., 2011). A potential promising role is reserved for low input high diversity (LIHD) biomass coming from (semi-) natural grasslands, heathland, swamps, multifunctional forests and small landscape elements (e.g. road verges) (Caron et al., 2003; Tilman et al., 2006; Bervoets, 2008; Velázquez-Martí et al., 2011). Within these LIHD systems, regular management practices with removal of residues are needed to maintain and/or increase the nature value (Caron et al., 2003) or to ensure public safety. Currently, these 


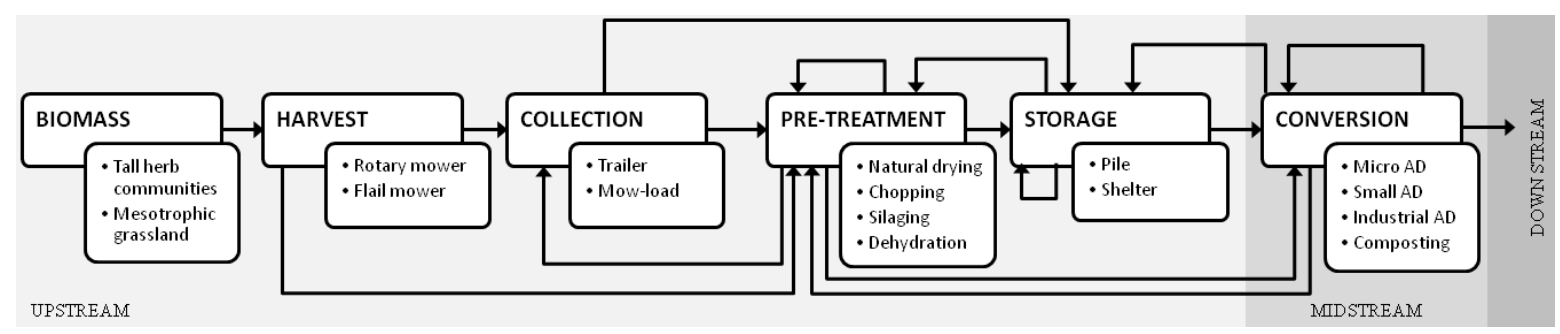

Figure 4: Conceptual model of the studied LIHD-to-bioenergy supply chain (AD=anaerobic digester)

management residues are left in the field as waste product (Caron et al., 2003; Kuiper and Caron, 2003; Bervoets, 2008).

To illustrate the functionalities and possibilities of OPTIMASS, scenario and sensitivity analyses are performed based on the supply of biomass derived from low input high diversity (LIHD) systems to anaerobic digesters or composting facilities in the Limburg province (Belgium). The biomass products and operations included in this LIHD biomass supply chain are defined based on figure 1 (De Meyer et al., 2013a). The result is summarised in figure 4, while the supply network is presented in figure 5. Furthermore, the required attributes and attribute values are defined and summarised in Appendix B (Supplementary material). Data and assumptions are retrieved from databases such as EcoInvent (Ecoinvent Centre, 2007) or peer-reviewed literature and expert opinions.

\subsection{Biomass supply}

Based on the research of Van Meerbeek et al. (2014), two LIHD product types have been selected: i.e. biomass from tall herb communities and biomass from mesotrophic grassland. The locations and corresponding areas of these product types are derived from the biological value map for the province of Limburg in Flanders (Instituut voor Natuurbehoud, 2001) resulting in 19993 sites. Considering the illustrative character of this use case, the 19993 sites are aggregated to 105 sites. This allows the graphic display of the results in a orderly manner. The aggregation to 105 sites is meant to retain the distribution of the number of sites between the two biomass types (27\% tall herb communities and $73 \%$ mesotrophic grassland) and to reflect the density of the sites within the area. Therefore, GISsoftware is used to create a density map (resolution: $250 \mathrm{~m} \times 250 \mathrm{~m}$ ) for each biomass type representing the number of sites and the total area of the sites within each pixel. This density map is used to define spatially balanced points (77 sites with mesotrophic grassland and 28 sites with tall herb communities). Then, the area of the 105 aggregated sites is calculated by assuming that feedstock is delivered from the original sites to the nearest selected site of the same type. The distance is also considered in the energy needed for the management of the harvesting and collection equipment. The attribute values to represent the biomass types are summarised in table B.4 (Supplementary material).

A range of harvesting equipment is available to harvest biomass from tall herb communities and mesotrophic grasslands. This use case concentrates on the two harvesting types most frequently applied during the maintenance of LIHD systems, i.e. rotary mower and flail mower (Departement Leefmilieu, 2006, 2011; Inverde, 2012). Both harvesting types have advantages and disadvantages. In general, a rotary mower is more nature friendly, but also more expensive because additional chopping operations are needed before conversion to energy (Inverde, 2012). Because rotary mowers are not able to harvest ligneous biomass, it is assumed that they can only be used to harvest biomass from mesotrophic grasslands. A flail mower cuts biomass immediately in small pieces, but is known to be more destructive for the immediate environment (Inverde, 2012). Flail mowers are more robust allowing the harvest of ligneous biomass. It is assumed that flail mowers can be used to harvest both LIHD biomass types. The attribute values to represent the harvesting types are summarised in table B.5 (Supplementary material).

To collect the harvested products, two collection types are considered, i.e. a tractor with trailer and a mow-load combination (Departement Leefmilieu, 2011). A tractor with trailer is the most general collection option. It is used to collect the biomass some time after the harvest operation with the rotary mower. In the period between harvest and collection, the biomass can be dried or chopped. The mow-load combination collects the feedstock during the harvesting operation and can be combined with the flail mower and the rotary mower. In case of the rotary mower, the biomass can be chopped during collection. No other pre-treatment operations are allowed at the biomass production site when the mow-load combination is used. Table B.6 (Supplementary material) shows the attribute values of the 
described collection types. In case of the mow-load combination, the energy attribute values reflect the extra energy related to the need of a larger tractor required for the mow-load combination.

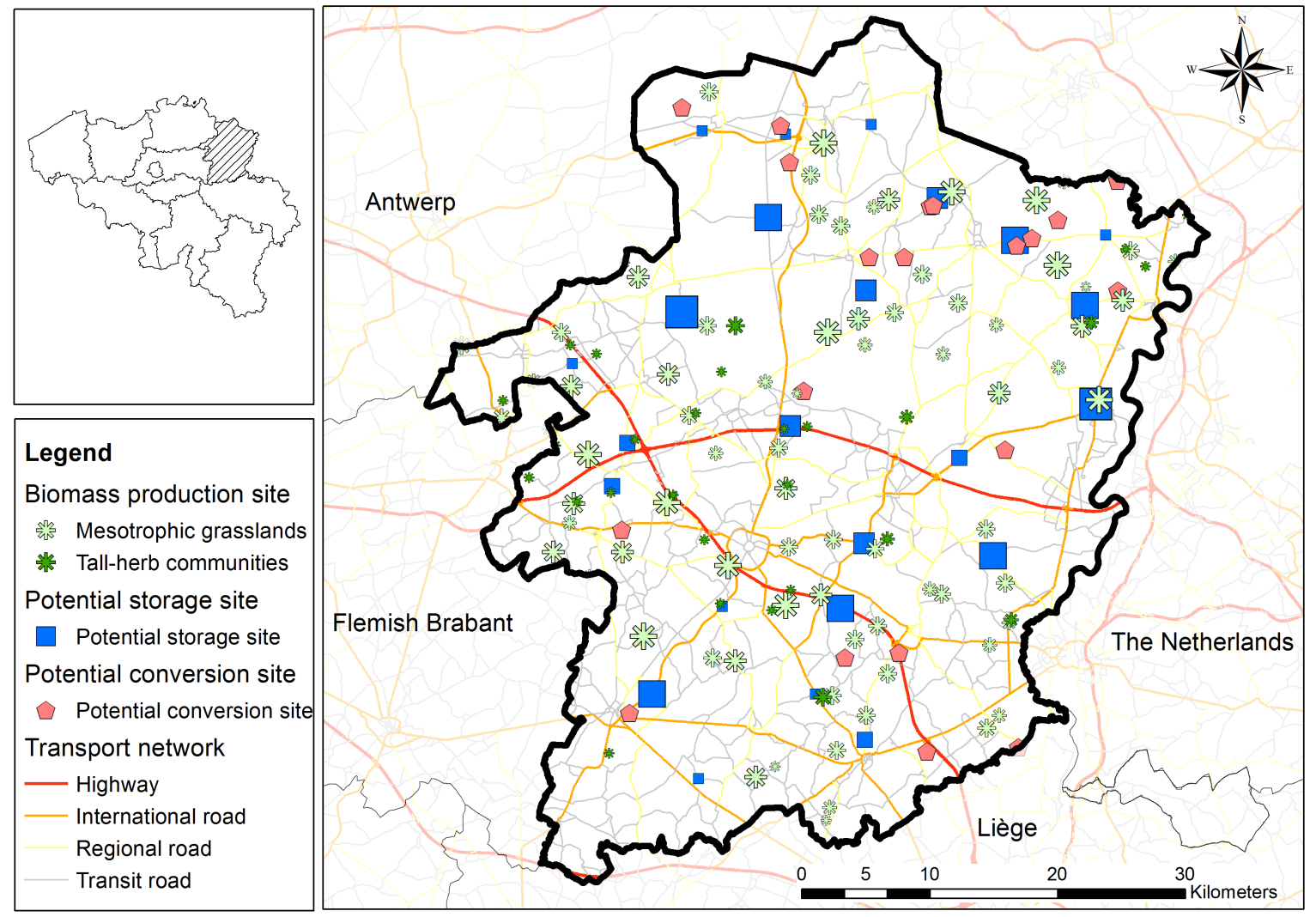

Figure 5: Considered bioenergy network in the Limburg province (without the municipality of Voeren)

\subsection{Storage}

Due to a lack of real-world data, the location of storage sites is fictitious. Twenty-four storage sites are defined considering the location of highway access points, conversion sites and biomass production sites (Figure 5). The number of storage sites is a trade-off between the clear display of the results and the illustration of the functionalities of the MILP. A storage site can consist of an open-air pile (capacity range: $7000-52500 \mathrm{~m}^{3} \mathrm{y}^{-1}$ ) or a covered shelter (capacity range: $35000-175000 \mathrm{~m}^{3} \mathrm{y}^{-1}$ ). All biomass, whether or not pre-treated can be stored in a pile except for the dried intermediates. In a shelter, only dried intermediates are stored. Chopping operations are allowed at each storage site, while ensilaging is only permitted at sites characterised as 'pile' (because in practice silage is not sheltered). The values of the storage type attributes are summarised in table B.7 (Supplementary material).

\subsection{Conversion}

Thirteen anaerobic digesters exist in the Limburg province of which 4 are registered at the Flemish compost organisation, VLACO (VLACO, 2011). The anaerobic digester converts manure from animal husbandry, agricultural residues and/or organic biological waste into (mainly) biogas and digestate. The biogas is used to generate heat and electricity using a combined heat and power (CHP) installation while the digestate can be used as e.g. fertiliser. Based on the capacity, three types of digesters are distinguished: i.e. micro scale anaerobic digesters (MAD), farm scale anaerobic digester (FAD) and industrial anaerobic digester (IAD). Furthermore, seven composting facilities are located in Limburg and registered at VLACO (VLACO, 2011). These facilities do not generate bioenergy, but can be important in the supply chain because the dehydrated digestate from the anaerobic digesters can be converted into compost. Table B.8 (Supplementary material) summarises the attribute values for the conversion types including the 
requirements of the products types. All pre-treatment types, except ensilaging, are allowed at the conversion site. Figure 5 indicates the locations of these sites. The real distribution of the conversion types is presented in figure 6 .

\subsection{Pre-treatment}

Pre-treatment operations are essential to achieve the biomass characteristics that will allow efficient storage, transport and conversion (Rentizelas et al., 2009). Although a large variety of pre-treatment types exists, this use case is limited to two pre-treatment types regularly applied in LIHD biomass management: i.e. chopping and ensilaging. Dehydration is only applicable to digestate and is required for further processing to compost. As mentioned in the paragraphs above, pre-treatment operations can occur at the biomass production site, at the storage site and at the conversion site. At the biomass production site, the allowed pre-treatment depends on the harvesting and collection types to be applied. Table B.9 (Supplementary material) summarises the attribute values for the pre-treatment types while table B.10 (Supplementary material) represents the characteristics of the intermediates.

\subsection{Transport}

The use case addresses a small area (i.e. $2422 \mathrm{~km}^{2}$ ) which makes the use of the railway or waterway network unlikely. Therefore, tractor and truck are chosen to be the two possible transport types. In this way, the multi-modal capabilities of the MILP model can be illustrated. The transport distances are retrieved from the Navstreet (2011.3) database (NAVTEQ, 2011) which implies that real transport distances are considered. For truck transport, the driving directions and restrictions from Navstreet are considered to determine the shortest path between sites $\left(d_{x y}^{z}\right)$. For transport by tractor, it is assumed that tractors may not access the highway, but are allowed to access all other roads. Moreover, in tractor transport no road hierarchy is considered to define the shortest path between sites $\left(d_{x y}^{z}\right)$. Table B.11 (Supplementary material) summarises the attribute values for the transport types.

\subsection{Extra product types}

The LIHD biomass alone cannot fulfil the requirements set by the conversion facilities (i.e. mainly the moisture content requirement). Also, LIHD biomass is meant to be used as a co-product in the digestion or composting process. Therefore, extra product types are defined which are available for conversion. However, the supply chain of these products is not optimised. Biodegradable waste, cow manure and pig slurry are chosen as extra products based on the high availability in Flanders and their high moisture content. Table B.12 (Supplementary material) summarises the attribute values for the extra product types.

\subsection{Demand}

To optimise this biomass-based supply chain, it is assumed that $90 \%$ of the capacity of the anaerobic digesters registered at VLACO must be achieved. This is translated into a total electricity demand of at least 217314 GJ and a total heat demand of at least 289750 GJ. An electricity surplus of $10 \%$ and a heat surplus of $30 \%$ are allowed. The demand corresponds to the needs of \pm 17250 households (considering an average electricity consumption of $3500 \mathrm{kWh}$ per household) which is $5 \%$ of the households in Limburg. It must be noted that the energy demand by households only covers $15 \%$ of the total energy demand in Flanders (MIRA, 2011). In addition, a compost demand of 74000 ton is assumed, representing the compost need in Limburg (i.e. 1/5 of the compost demand in Flanders (Braekevelt and Schelfhout, 2013)).

\section{Scenario analysis}

To illustrate the functionalities and possibilities of OPTIMASS, three scenarios are defined based on the use case described in section 4. The first scenario considers the current conversion facilities in Limburg. A second scenario investigates the addition of one or more anaerobic digesters to meet an increased electricity demand. The third scenario explores the optimal configuration of the conversion facilities considering the existing locations as potential locations. Each scenario is optimised according to the maximal net energy output. The scenarios are solved with an Intel Core i5 CPU 2.67 GHz with 4 GB RAM on a 64-bit platform. The models generated for the considered scenarios contain between 1288012 and 1288233 constraints, governing between 632943 and 633244 decision variables, including between 3344 and 3644 integer and binary variables. The solution times range between 1.5 and 10 minutes depending on the scenario considering a tolerance from the optimal integer solution set to $1 \%$. The main results are summarised in table 1 and 2 and figures 6 to 8 . 
Table 1: Summary of the energy demand (GJ), gross energy output (GJ), energy input (GJ) and corresponding net energy output (GJ)

\begin{tabular}{l|rrr}
\hline & SCENARIO 1 & SCENARIO 2 & SCENARIO 3 \\
\hline Energy demand & 507064.0 & 715214.6 & 507064.0 \\
Gross energy output & 570660.9 & 805306.3 & 566160.2 \\
Energy input: & & & \\
$\quad$ Transport & 107554.6 & 125993.3 & 94854.0 \\
$\quad$ Harvest & 8258.5 & 8355.2 & 7504.8 \\
Collection & 30053.5 & 30420.9 & 27183.5 \\
Pre-treatment & 13432.6 & 23174.9 & 10997.3 \\
$\quad$ Storage & 6195.0 & 17395.0 & 5355.0 \\
$\quad$ Conversion & 144418.8 & 196680.0 & 128850.0 \\
$\quad$ Extra product & 17976.4 & 25748.4 & 17418.8 \\
Net energy output & 242771.5 & 377538.6 & 273996.9 \\
\hline
\end{tabular}

\subsection{Scenario 1: Optimising the use of the current infrastructure}

Scenario 1 considers the LIHD biomass supply chain including the currently present conversion facilities in Limburg. This implies that the binary variable $Y_{k}^{c}$ is pre-set to 0 or 1 to define the (non-)existence of a conversion type at each conversion site. In a similar way, the storage type is fixed at each storage site to represent the current situation (although fictional). The resulting optimal supply chain is presented in figure 6. In this supply chain, 239045 GJ of electricity, $331616 \mathrm{GJ}$ of heat and 84000 ton of compost are produced. However, around $57 \%$ of the total energy output is needed to perform all operations in the chain of which $34 \%$ relates to the transport of the biomass products (Table 1).

In the current situation, mowing with a flail mower is preferred ( $81 \%$ of mesotrophic grasslands and $100 \%$ of tall herb communities). This is mainly because a flail mower does not require further chopping of biomass (Inverde, 2012) which reduces the energy input. Table 2 presents the biomass mixture converted at each facility. All anaerobic digesters require $50 \%$ extra product due to the high moisture content requirement in the anaerobic digesters and the mixture constraint that defines that not more than half of the mixture may consist of extra products. To investigate the possibilities of LIHD biomass, a scenario has been optimised in which no moisture content requirements are considered (Section 7). These high moisture content requirements also induce the pre-treatment of mesotrophic grasslands to silage since this operation increases the moisture content of the biomass. Since extra energy is needed to open and manage storage facilities and to perform the pre-treatment operations, OPTIMASS makes a trade-off between the use of extra products, the conversion to silage and the immediate use of harvested biomass to meet the high minimum moisture content requirement at the conversion facility. In all anaerobic digesters (except CL2) silage has been included in the biomass mixture. Table 2 also indicates that composting facilities only converted biomass from mesotrophic grasslands into compost. This is the case in all scenarios. This is probably because more biomass from mesotrophic grasslands is available and the tall herbs are preferred in the anaerobic digesters due to the higher biogas content.

In addition, all biomass is transported by tractor. This is mainly due to the small study area and corresponding short distances between facilities. This implies that the tractor with higher energy input per kilometre but avoiding energy input for transshipment is more beneficial than the truck with lower energy input per kilometre and higher energy input for transshipment (Table B.11 (Supplementary material)). The influence of the distance on the choice of transport type is investigated in section 6.3. Furthermore, figure 6 indicates that biomass is delivered from biomass production sites located in the vicinity of storage and conversion facilities to reduce energy input related to transport. However, to meet the feeding requirements of the industrial anaerobic digester in the north of the province of Limburg, biomass, whether or not ensilaged, is transported over longer distances. 


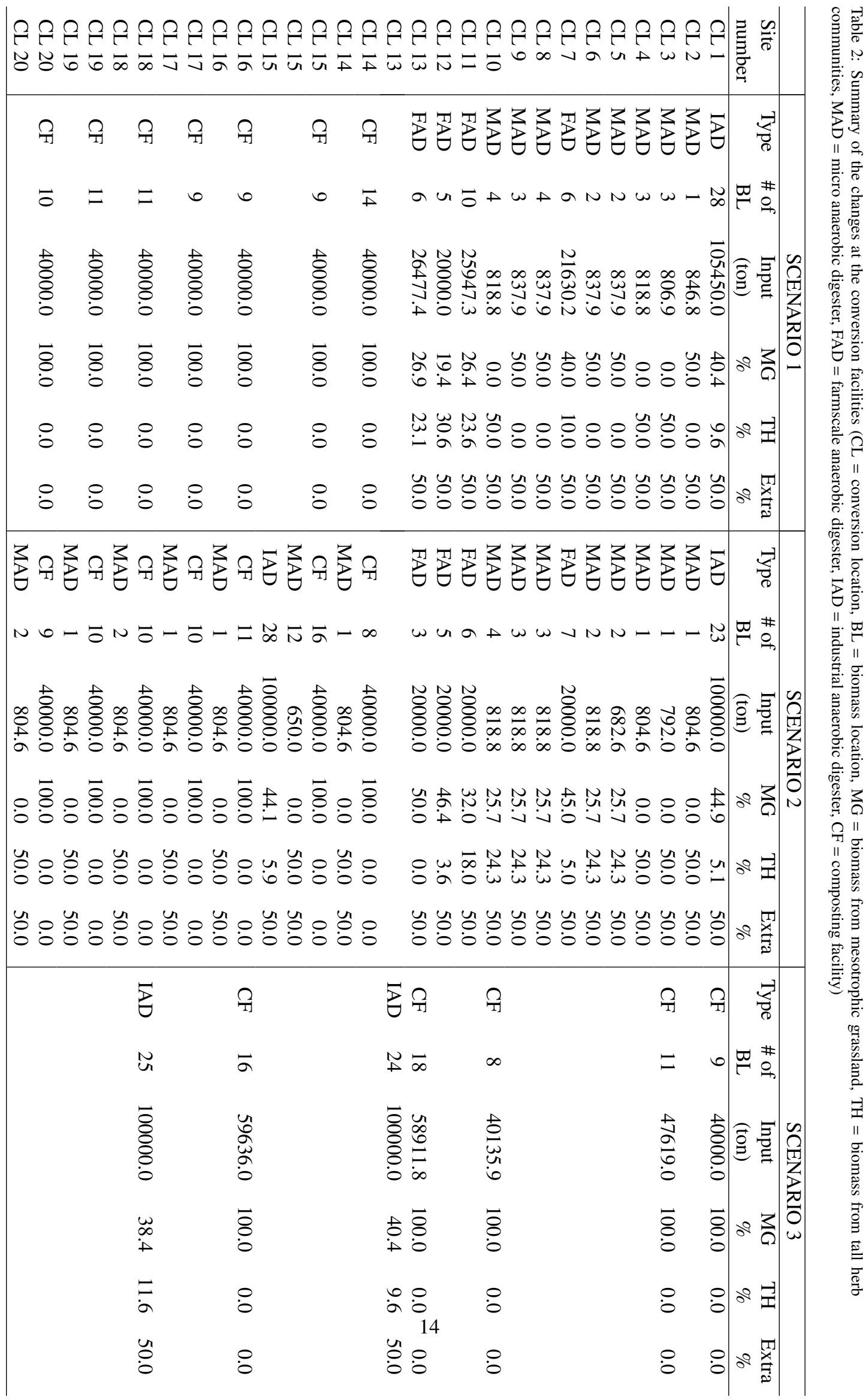



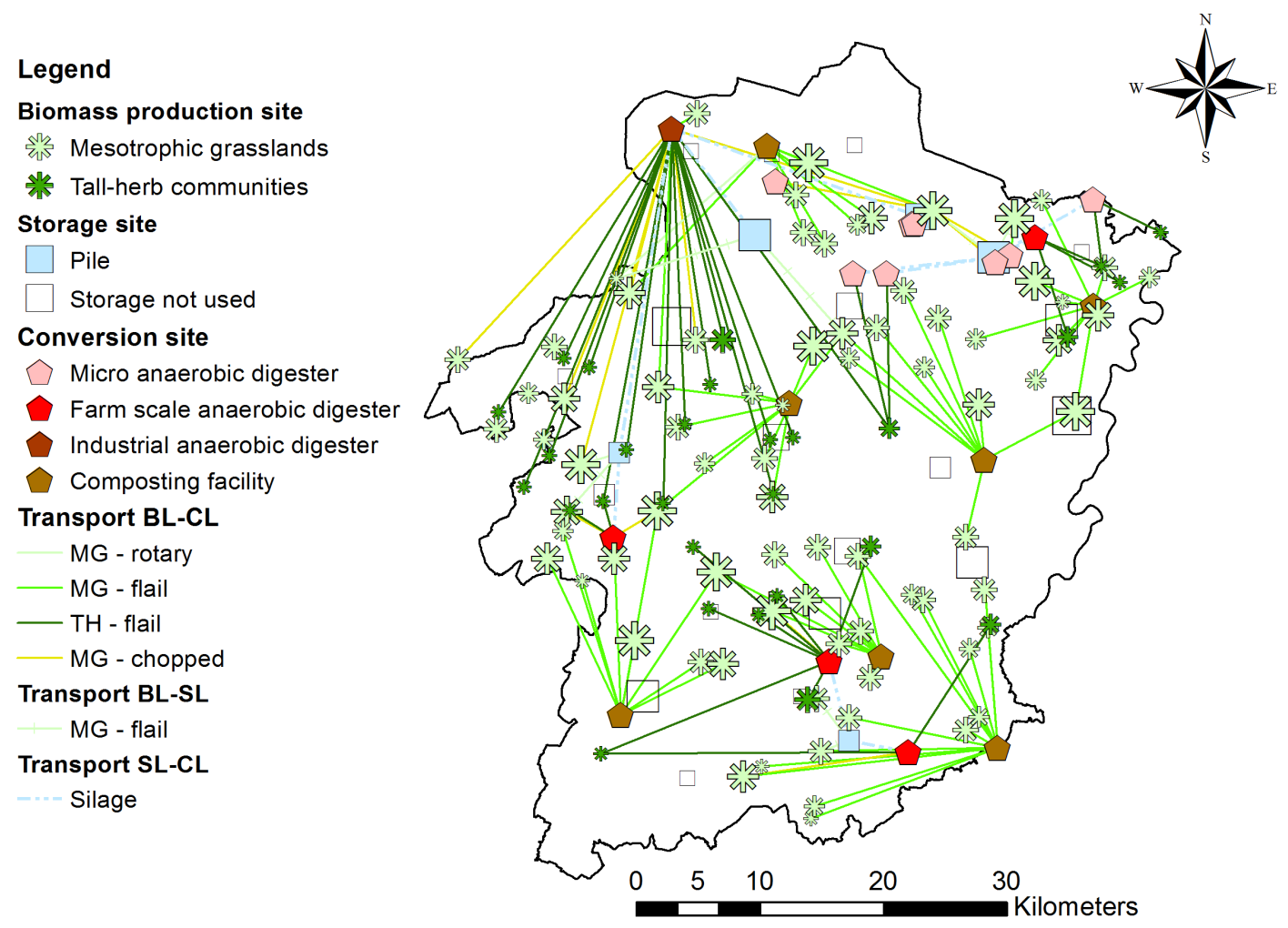

Figure 6: Result scenario 1: Optimising the use of the current infrastructure $(\mathrm{MG}=$ mesotrophic grassland, $\mathrm{TH}=$ tall herb community)

\subsection{Scenario 2: Where to build new anaerobic digestion facilities?}

By 2020, Belgium is obliged to produce $13 \%$ of its final energy consumption from renewable energy sources (European Parliament \& Council, 2009). Based on the current bioenergy share of around $45 \%$ (www.energiesparen.be), Limburg will have to produce around 306522 GJ of electricity from biomass. The capacity of the existing anaerobic digesters cannot meet this electricity demand. Therefore, this scenario determines the optimal location(s) to build one or more new anaerobic digesters, the type of each digester and the consequences for the configuration of the LIHD supply chain. In this scenario it is assumed that if dehydration occurs at a site with an anaerobic digester, the energy input related to operation and management is reduced by $50 \%$ because the heat produced by the digester can be used. The resulting supply chain is presented in figure 7 .

In comparison to scenario 1, six micro anaerobic digester and one industrial anaerobic digester are added to the supply chain. This results in an increase to 337142 GJ of electricity and 468132 GJ of heat (i.e. an increase of about $30 \%$ ) (Table 1). All anaerobic digesters are added to the existing composting facilities (and not to existing anaerobic digesters). This is explained by the fact that dehydrated digestate can be used in the composting facility and by the assumption that the energy input related to operation and management for dehydration is reduced by $50 \%$. The results show that when the anaerobic digester is added, all available digestate is dehydrated and converted to compost in the composting facility at the same site. If digester and composting facility are not located at the same site, digestate is transported to a neighbouring composting facility (Figure 7).

Although extra biomass is necessary to run the extra anaerobic digesters, proportionally less energy is required to perform all handling and transport operations in the chain (53\% versus $58 \%$ in scenario 1$)$. In other words, to produce $30 \%$ extra energy output, the energy input increases by only $23 \%$ (Table 1 ). This is mainly because the extra harvest and collection operations lead to only a small increase in energy input as well as the energy input for transport. This is probably because digestate from the same site is used in the composting facilities which reduces the need for biomass delivery. This small increase must compensate the extra energy input related to the management of the new conversion facilities. 
In comparison to scenario 1, most anaerobic digesters convert 1-10\% less biomass with the exception of CL 5 which converts even $18 \%$ less biomass (Table 2). This results in a reduction in the energy output of these facilities with $12 \%$. In total, $22 \%$ more biomass sites must be harvested in comparison to scenario 1 . However, this is compensated by the introduction of the new anaerobic digesters at the composting facilities. These results highlight the competition for biomass between the conversion facilities in the area.
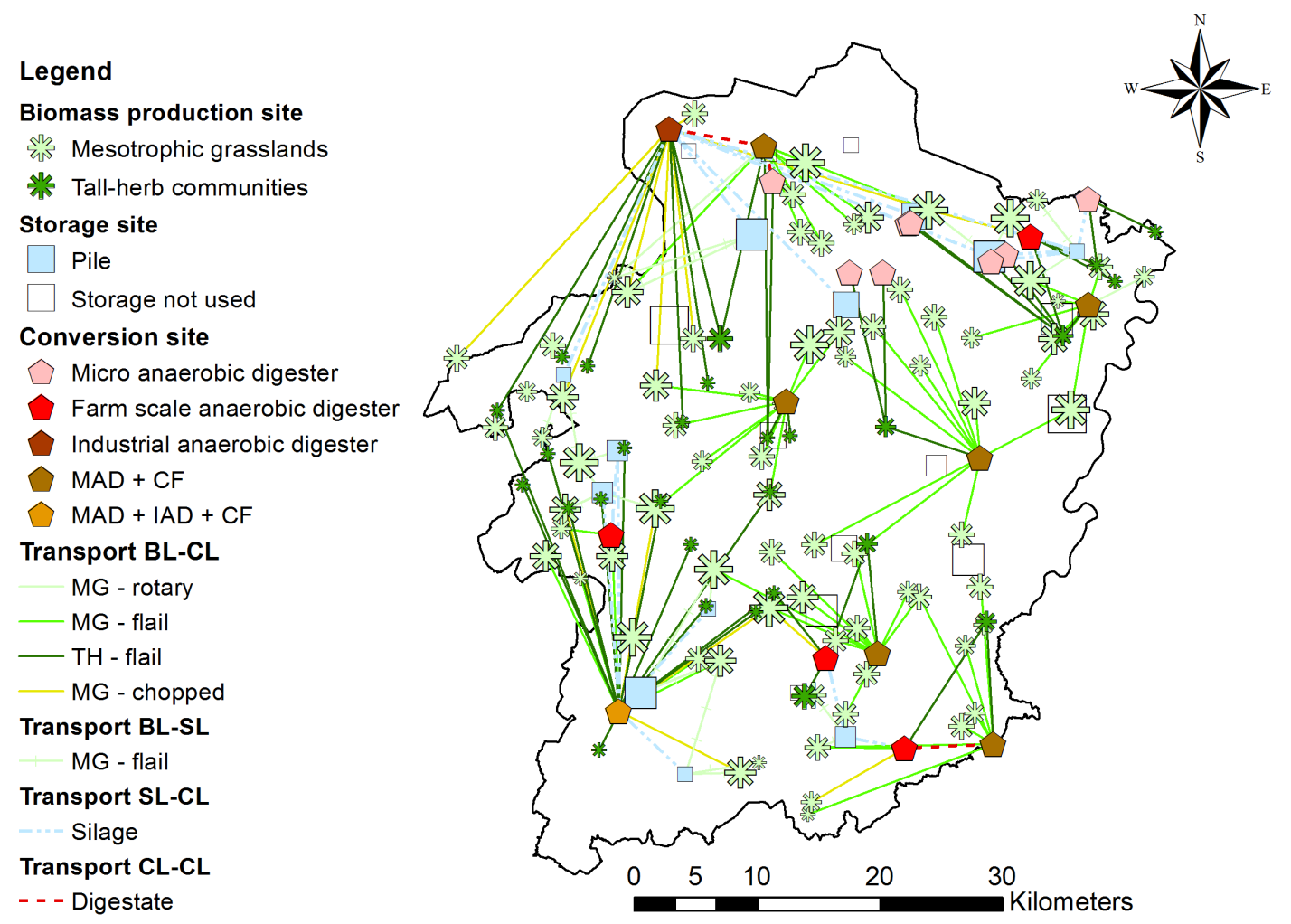

Figure 7: Result scenario 2: Where to build a new anaerobic digestion facilities ? (MAD = micro anaerobic digester, IAD $=$ industrial anaerobic digester, $\mathrm{CF}=$ composting facility, $\mathrm{MG}=$ mesotrophic grassland, $\mathrm{TH}=$ tall herb community)

\subsection{Scenario 3: Optimal configuration of conversion facilities}

In this scenario, OPTIMASS is used to optimise the configuration of the conversion facilities in the province of Limburg. Although OPTIMASS allows the introduction of other (e.g. random) potential locations, the potential locations to construct conversion facilities assumed in this scenario are the ones presented in figure 5 . This because at these locations conversion facilities are certain to be admitted. The resulting supply chain is presented in figure 8 .

In comparison to scenario 1 , the gross electricity and heat generation decreases to $566160 \mathrm{GJ}(-0.8 \%)$. However, the net energy output increases to $273997 \mathrm{GJ}(+11 \%)$. This implies an energy reduction of $12 \%$ mainly due to a reduction in pre-treatment $(-20 \%)$, storage $(-16 \%)$ and transport $(-13 \%)$ energy input (Table 1$)$. In addition, $26 \%$ less biomass sites have been harvested (Table 2 ). To meet an equal energy and compost demand, this optimal supply chain only requires 3 storage facilities, 2 industrial anaerobic digesters and 5 composting facilities. This is in contrast with the 5 storage facilities, 13 anaerobic digesters and 7 composting facilities in the current situation (Scenario 1) (Table 2). 2 industrial anaerobic digesters are proposed rather than the many smaller anaerobic digesters in scenario 1. This implies that, at this scale, centralised conversion is more beneficial than decentralised conversion of biomass. Of course, the downstream demand is not considered in this analysis. Figure 8 shows a link between the location of the selected conversion sites and the density of the biomass production sites. This implies that the transport distance is one of the driving parameters in the model. Although at one site, an industrial digester is combined with a composting facility, no transfer of digestate occurs. This is due to the high energy input related to dehydration (Table B.9 (Supplementary material)). 

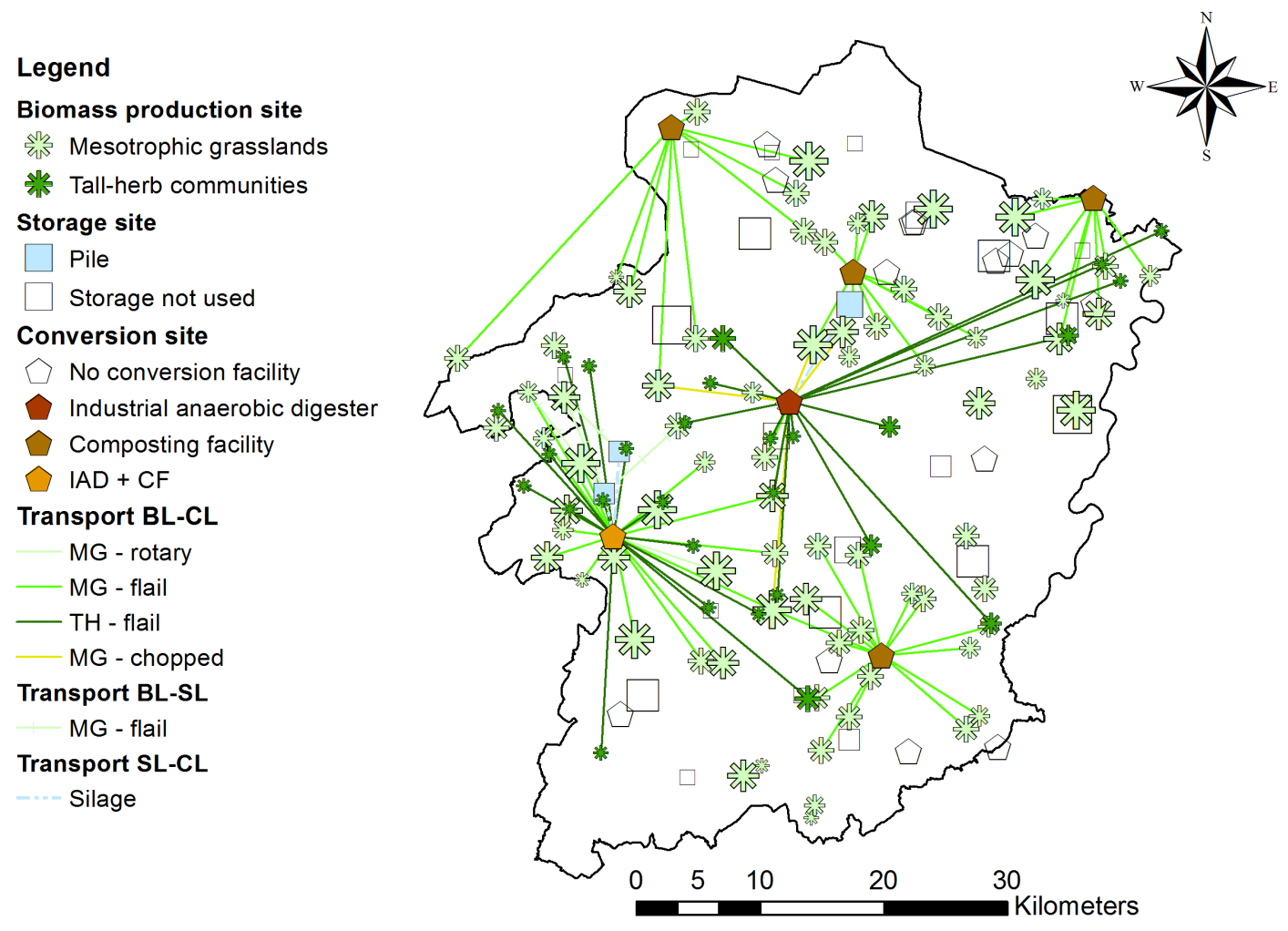

Figure 8: Result scenario 3: Optimal configuration of conversion facilities $(\mathrm{IAD}=$ industrial anaerobic digester, $\mathrm{CF}=\mathrm{composting}$ facility, $\mathrm{MG}=$ mesotrophic grassland, $\mathrm{TH}=$ tall herb community)

\section{Sensitivity analysis}

Although uncertainty clearly influences decisions in the supply chain (Shabani et al., 1998), OPTIMASS, as a deterministic model, cannot consider this uncertainty. An appropriate way to address this limitation is to perform a sensitivity analysis to investigate the effect of uncertain biomass production and energy (electricity) demand on the net energy output and configuration of the supply chain. In addition, the effect of the transport distance is investigated in section 6.3. The analysis is applied to the LIHD supply chain optimised in scenario 1 (Section 5.1).

\subsection{Sensitivity to uncertainty in harvestable biomass production}

One of the barriers in the development of a sustainable bio-energy industry is the uncertainty in biomass availability (a.o. due to the weather conditions). To investigate the effect of this uncertainty, 5 scenarios are addressed considering a certain percentage of the harvestable biomass production (i.e. very low (35\%) - low (50\%) - normal $(100 \%)$ - high $(150 \%)$ - very high $(200 \%))$. The percentage related to scenario "very low" is determined using a trial and error approach to find the lowest percentage resulting in a feasible solution without changing constraints or parameters. The normal scenario equals scenario 1 . The resulting optimal supply chains are presented in Appendix C (Supplementary material).

In this sensitivity analysis, the energy demand as described in section 4.7 must be met in each scenario. Figure 9 indicates that the energy input decreases as the available biomass production increases. Since a steady gross energy demand is considered, this implies that the net energy output increases as more LIHD biomass is available. In comparison to the normal scenario $(100 \%)$, the energy input increases by $21 \%$ as biomass production is very low and decreases by $3.5 \%$ as biomass production is very high. Furthermore, figure 9 suggests that the energy input and corresponding net energy output stabilise when more biomass is available $(>100 \%)$. This is mainly due to the 


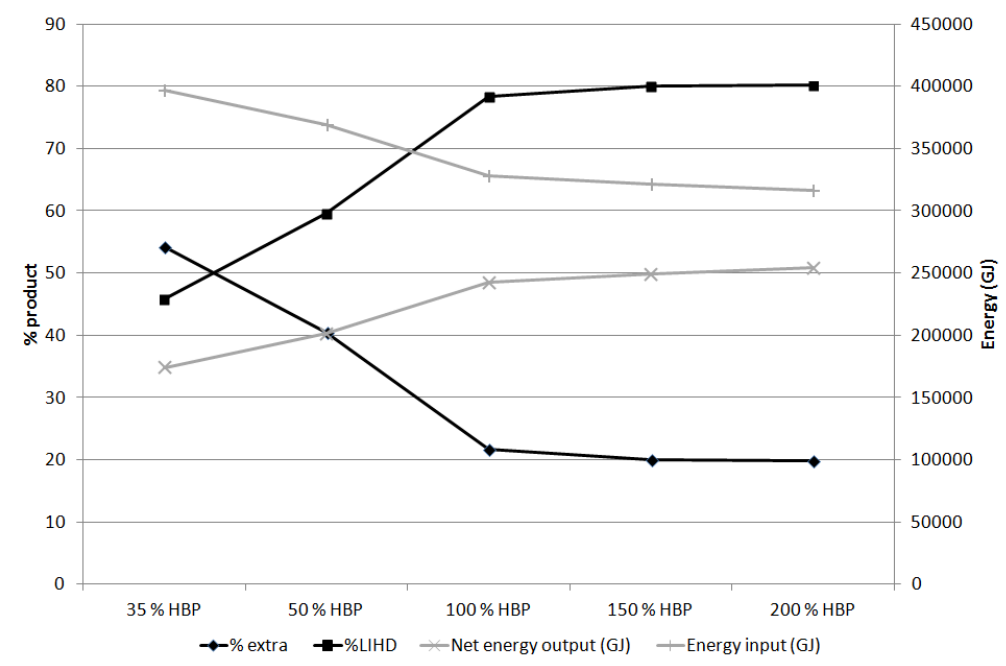

Figure 9: Usage of LIHD biomass and extra product use and amount of energy input and net energy output as a function of the portion of available biomass

demand constraint which limits the total amount of biomass needed and due to the constraints defining the moisture content requirements in the conversion facility limiting the amount of biomass allowed in the conversion process.

This stabilisation is also indicated in figure 10 since the energy inputs related to the different operations hardly change in the scenarios with higher biomass availability. In these scenarios, the energy inputs related to harvest and collection operations are higher than the energy input for pre-treatment operations which is in contrast to the scenarios with a lower available amount of biomass. These scenarios result in high pre-treatment energy inputs because digestate from anaerobic digesters must be dehydrated to be used in the composting facilities (to meet the mixture and feeding rate requirements). In addition, more biomass is pre-treated to silage before digestion to increase the moisture content. The higher pre-treatment energy input is also related to a higher number of storage facilities opened in the very low (10 storage facilities) and low scenario (6 storage facilities) in comparison to the normal (5 storage facilities) and higher scenarios (4 storage facilities). In case of LIHD biomass shortage, the higher energy input also relates to the larger quantity of extra product in the conversion process (Figure 9 and 10) to meet the minimum feeding rate of the conversion facility. Furthermore, figure 10 indicates that the energy input related to transport decreases when more biomass becomes available. This is obvious since more biomass can be harvested at each site and less sites must be touched to obtain the same amount of biomass. If only $35 \%$ of the harvestable biomass production is available, the energy input for transport is similar $(+0.6 \%)$ as in the normal scenario. Although less harvested biomass must be transported, a high energy input is related to the transport of digestate. In contrast, if only $50 \%$ of the biomass is available, the energy input related to transport drops with $11 \%$ in comparison to the normal scenario. This is mainly related to the fact that less biomass can be harvested and a smaller quantity of digestate is transported.

\subsection{Sensitivity to uncertainty in energy demand}

This sensitivity analysis investigates the influence of uncertainty in energy demand on the energy output and configuration of the supply chain. First, the LIHD supply chain resulting in the highest possible net energy output is determined. This encompasses optimisation without considering the demand constraints. This results in a total electricity production of 251003 GJ and a total heat production of 348138 GJ. Starting from 0 GJ, this energy output is divided into 5 equal intervals of which the corresponding electricity and heat production are applied as the energy demand to be considered in the optimisation of the supply chain. The analysis assumes that all existing composting facilities are open and the existing anaerobic digestion facilities can be opened because it is infeasible to claim a (very) small energy demand when all anaerobic digesters must be opened. Consequently, the analysis indicates which anaerobic digestion facilities should be used to meet the specified demand. The resulting supply chains are summarised in Appendix C (Supplementary material). 


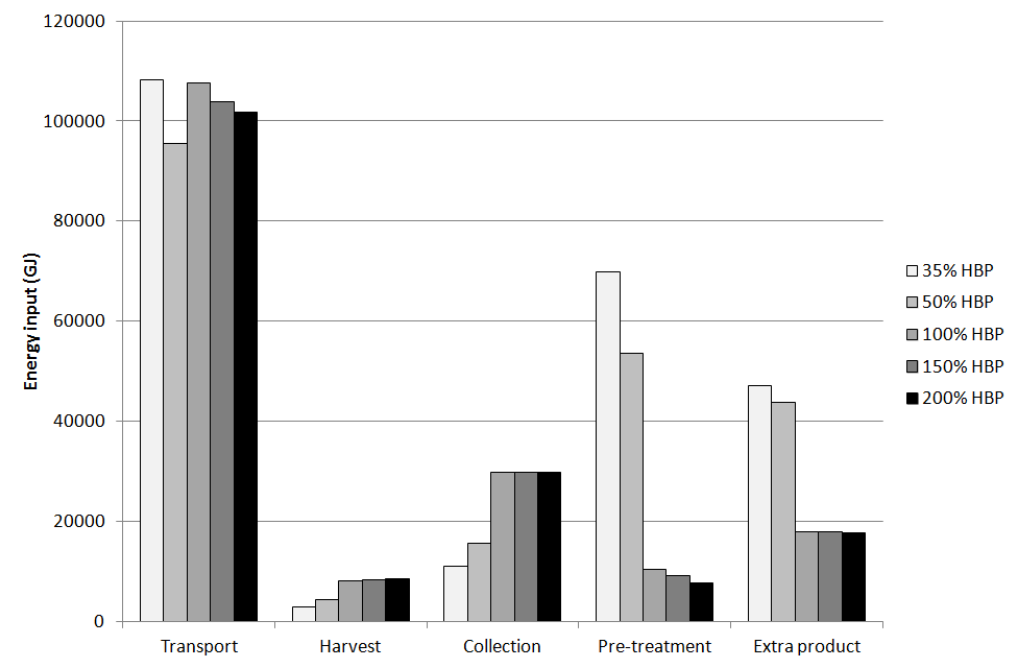

Figure 10: Contribution of different operations to the total energy input related to the portion of available biomass

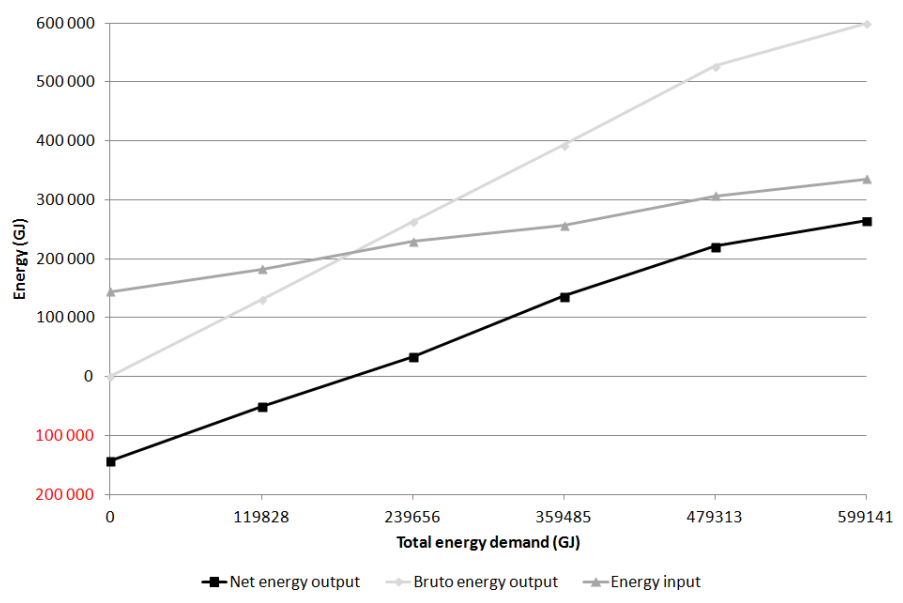

Figure 11: Optimal net energy output (GJ) as a function of energy demand (GJ)

If no energy is requested, only the composting facilities are in use to meet the compost demand (Figure C.17 (Supplementary material)). It is clear that this supply chain does not produce energy, but only requires energy. Figure 11 presents the energy output, energy input and net energy output as a function of the energy demand. This shows that the ratio between energy input and gross energy output decreases. This implies that the difference between gross energy output and net energy output decreases and therefore the supply chain becomes more efficient when more energy is demanded. In addition, an energy demand of 191775 GJ results in a supply chain in which the gross energy output equals the energy input.

Table 3 in combination with the figures in Appendix C (Supplementary material) gives an indication of the changes within the supply chain when energy demand changes. In the scenario in which no energy must be produced, only composting facilities are in use. Since the moisture content requirements of the composting facilities are less restrictive, the biomass is mown with a flail mower and directly collected with a mow-load combination which makes the collected product immediately usable for composting. Therefore, no energy is needed for storage and pre-treatment. In this scenario, even no extra product is added. When the demand increases (demand 2), the two most centrally located farm scale anaerobic digesters are opened. No pre-treatment and storage operations are required since only a small amount of swine and cow manure is sufficient to meet the high minimum moisture content requirement. In the 
Table 3: Overview of the facilities opened in each demand scenario (with MAD = micro anaerobic digestion, FAD $=$ farm scale anaerobic digestion, $\mathrm{IAD}=$ industrial anaerobic digestion, $\mathrm{CF}=$ composting facility)

\begin{tabular}{l|c|ccccc}
\hline & Energy demand & Number of opened & \multicolumn{4}{|c}{$\begin{array}{c}\text { Number of opened } \\
\text { conversion facilities }\end{array}$} \\
& & storage facilities & MAD & FAD & IAD & CF \\
\hline Demand 1 & 0 & 0 & 0 & 0 & 0 & 7 \\
Demand 2 & 119828 & 0 & 0 & 2 & 0 & 7 \\
Demand 3 & 239656 & 1 & 0 & 4 & 0 & 7 \\
Demand 4 & 359485 & 0 & 8 & 1 & 1 & 7 \\
Demand 5 & 479313 & 2 & 8 & 3 & 1 & 7 \\
Demand 6 & 599141 & 5 & 8 & 4 & 1 & 7 \\
\hline
\end{tabular}

following demand scenario (demand 3), all farm scale anaerobic digesters are needed to meet the energy demand. A storage facility is added to convert a certain amount of biomass to silage. However, in demand 4, the storage facility disappears and the industrial anaerobic digester is opened in combination with all micro anaerobic digesters and the centrally located farm scale anaerobic digester. After this demand scenario, storage facilities must be introduced in which biomass is pre-treated to silage and farm scale anaerobic digesters are added to meet the energy demand. With the maximal possible energy output (demand 6), all conversion facilities are opened and 5 storage facilities are included to convert biomass from mesotrophic grasslands to silage (Figure C.22 (Supplementary material)). The resulting supply chain is quite similar to the optimised supply chain in scenario 1 . However, more biomass production sites have been harvested.

\subsection{Sensitivity to transport distance}

In the description of OPTIMASS, it has been stated that OPTIMASS can cope with multi-modal transportation networks. In this context, storage facilities are used as possible nodes where transshipment between transport modes can occur. However, in the scenarios investigated so far transport by tractor has been offered as the only optimal transport mode due to the small spatial extent of the use case. To present the possibility of multi-modal transport, the distance between points has been increased with a factor of respectively 2.5, 5, 10 and 15. The resulting supply chains are summarised in Appendix C (Supplementary material). Figure 12 points out the possibility to transship from tractor to truck occurs at a storage facility.

A gradual transition from tractor transport to truck transport is established. This transition is related to the energy input for transport and transshipment displayed in table B.11 (Supplementary material). In comparison to truck transport, transport by tractor is more energy expensive per kilometre while the energy input related to the transshipment operation is smaller. So, the larger the distance, the more interesting truck transport will become. This analysis indicates that, based on the values in table B.11 (Supplementary material), the tipping point between transport by tractor and transport by truck is about $80-100 \mathrm{~km}$. 

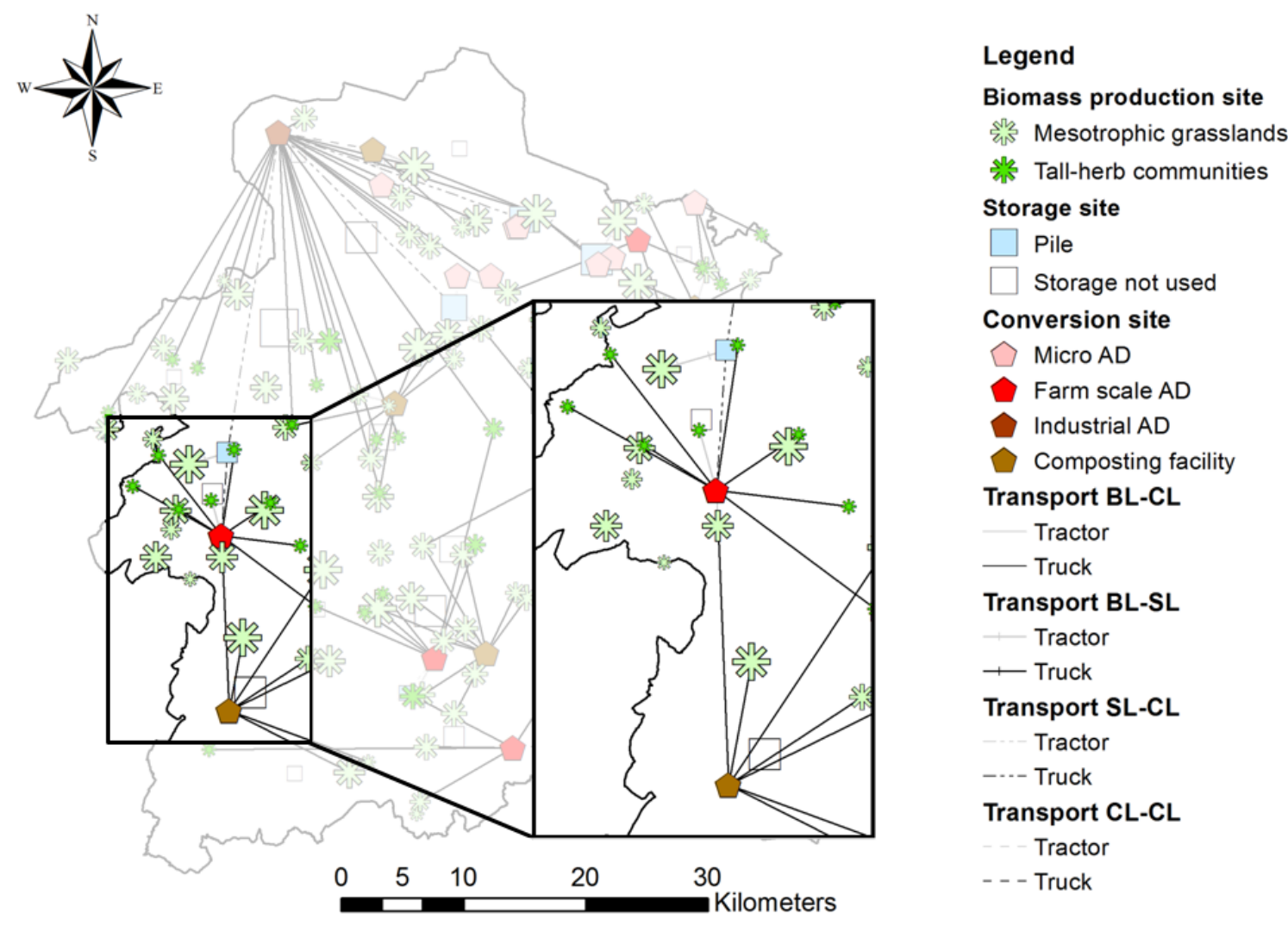

Figure 12: Detail of the optimised biomass-based supply chain - transport distance $\mathrm{x} 15$

\section{Discussion}

The decision making process is among others driven by the requirements related to the biomass characteristics imposed by the conversion facilities. The feeding rate defines the minimum required and maximum allowed quantity of biomass that can be transported to the conversion facilities which has an influence on the allocation pattern. The regulation of biomass mixture to be converted at the facility will define what kind of biomass will be delivered to the conversion facility. The moisture content and particle size requirements define in which format the biomass must be delivered. It is clear that to satisfy these requirements it is necessary to include changes in biomass characteristics due to harvest and pre-treatment operations. In this way, the biomass-based supply chain can be optimised in a comprehensive way. However, to keep track of and to optimise the changes in biomass characteristics, additional integer variables have been defined in OPTIMASS. So, the model can decide where to perform the pre-treatment operation by means of three binary variables $Y_{i}^{f p}, Y_{j}^{s p}$ and $Y_{k}^{c p}$. Additionally, two integer variables are included to optimise the harvesting equipment $\left(Y_{i}^{f h}\right)$ and collection equipment $\left(Y_{i}^{f g}\right)$ at the biomass production site. The computational intensity depends on the number of variables, more specifically the number of integer variables. Most existing models include integer variable to optimise the storage type $\left(Y_{j}^{s}\right)$ and the conversion type $\left(Y_{k}^{c}\right)$ at certain locations. So, although these extra integer variables improve the approach to reality, the computational time increases drastically. Therefore, in this paper the tolerance from the optimal integer solution has been set to $1 \%$ which makes it possible to obtain a near optimal solution in a reasonable amount of time (1.5 - 10 minutes). To analyse the deviation from the optimal result due to this tolerance, scenario 1 has been optimised without tolerance setting $(0 \%)$. This results in an identical solution, obtained in 394 minutes (in comparison to 1.5 minutes).

Furthermore, the scenario analysis indicates that the mixture converted at the anaerobic digester contains $50 \%$ of LIHD biomass and $50 \%$ of extra product (Table 2). This is due to the high moisture content requirement in the anaerobic digesters and the mixture constraint that defines that not more than half of the mixture may consist of extra 


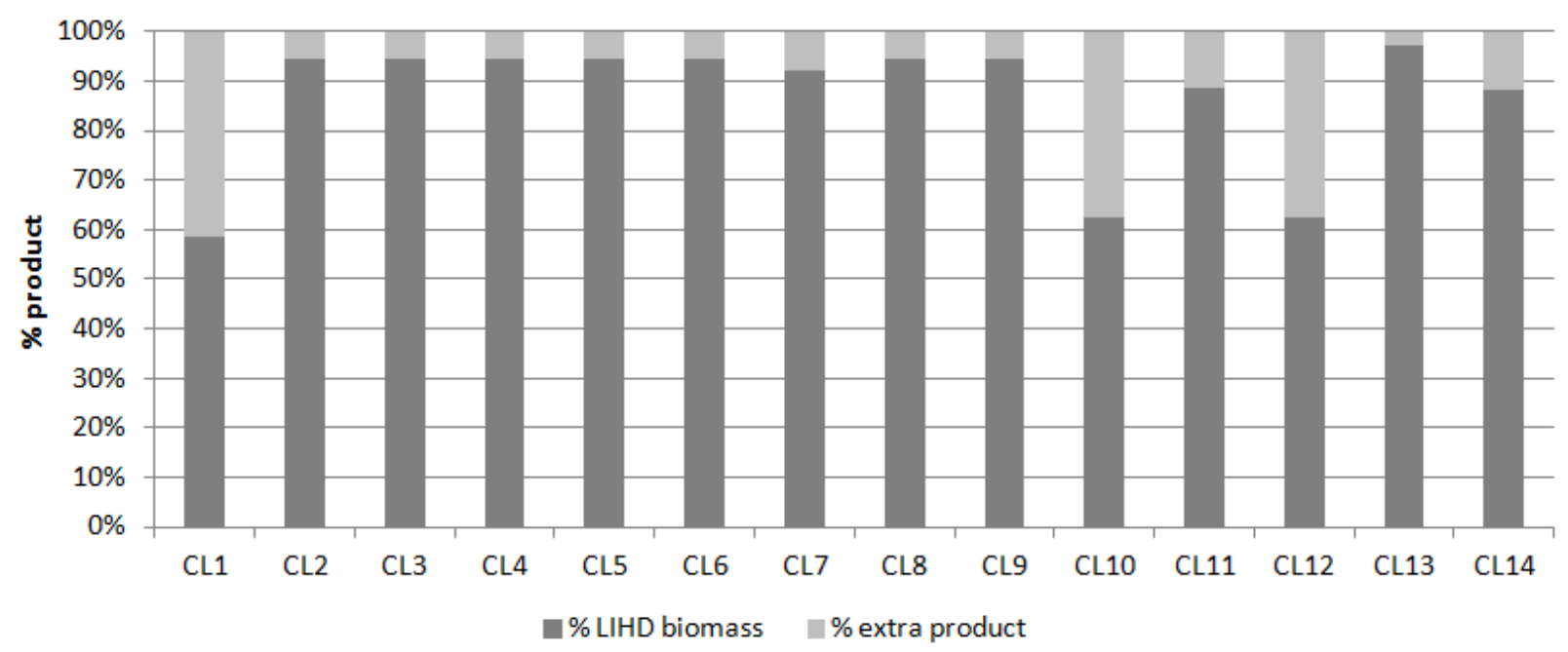

Figure 13: LIHD and extra product use and net energy output and input

products. Figure 9 indicates a decrease in the proportion of extra products needed in the complete supply chain when LIHD biomass is sufficiently present. However, at the anaerobic digesters a 50/50 distribution is still maintained. This relates to the fact that at the composting facilities no extra product is converted. To confirm the statement that the moisture content requirement is one of the main drivers in this use case, scenario 1 has been optimised without considering the moisture content requirements. In this supply chain $88 \%$ of LIHD biomass and $12 \%$ extra product are used to run the anaerobic digesters and conversion facilities in comparison to $78 \%$ of LIHD biomass and 22 $\%$ of extra product in scenario 1 . In addition, at each facility more LIHD biomass is converted than extra product (Figure 13). This implies that LIHD biomass is a promising source of biomass to meet the future biomass demand for bioenergy production.

To consider the supply chain in a holistic way, the model considers the re-injection of by-products from the conversion process in the supply chain. The influence of this possibility becomes clear when the available amount of biomass is reduced (Section 6.1). In this case, digestate is dehydrated to meet the feeding rate of the composting facilities. In this way enough biomass is available to run the composting facilities and to meet the energy demand. Without the possibility to re-use the by-product, no feasible solution can be found. However, the other scenarios do not use the dehydrated digestate. This is mainly due to the high energy input related to the dehydration process which makes it more profitable to harvest biomass at a production site and transport it to the conversion facility. The benefit to re-use (by-) products in other conversion processes is also highlighted in e.g. Van Dael et al. (2013).

Some scenarios do not open storage facilities in the optimal result. This is mainly due to the scale of the use case which causes the energy input to manage the storage site to be higher than the energy needed to transport the products directly to the conversion facility. In the other scenarios, storage facilities are only opened to convert the harvested biomass to silage. The main driver for this decision is the higher moisture content of silage in comparison to grass. However, the role of storage facilities is expected to become more clear when time issues are incorporated into the model and more tactical and operational decisions are optimised. In this case, seasonality in availability of biomass induces storage need to meet the constant feeding rate of the conversion facility or to reach a certain product state (e.g. moisture content). In this context, changes in biomass characteristics will be defined in function of time in comparison to the current model in which the specific characteristics of the different product types are fixed parameters. This imposes the use of typical average values (Table B.10 (Supplementary material)). However, due to the illustrative character of the use case, the use of average values is considered to be sufficient.

In literature, the energy performance of biogas plants is often defined as the net energy ratio determined by dividing the output energy with the energy input for the different operations (Hakuvainen et al., 2014). This ratio varies between 1.8 and $25 \%$ depending on the operations included. To be able to compare the energy performance in this paper, scenario 1 has been optimised without the use of composting facilities. In this way, only the energy 
input related to the digesters is considered. This results in a net energy ratio of $3.12 \%$ in which harvesting, collection, storage, treatment, conversion and transport input is included. This is within the wide range found in literature and summarised in Hakuvainen et al. (2014). Studies determining the net energy ratio of biogas plants based on biomass from cash crop farms come up with an energy balance between 6 and $13 \%$ (Helbig et al., 2008; Uellendahl et al., 2008). However, in these studies, a large part of the energy input relates to cultivation, production, use of fertilisers, etc. which is not required in the use of LIHD biomass.

A critical point in the implementation of OPTIMASS is the difficulty to identify reliable quantitative values for the various model parameters. Therefore, progress in other fields of research in order to provide reliable quantitative information (such as the biomass properties, the conversion process efficiency and yields, various costs, land availability etc.) is a critical factor in the performance and the applicability of the presented model in real situations (Papapostolou et al., 2011). In this paper the main goal is to illustrate the potential of OPTIMASS. The results indicate a direction of change, but do not intend to present the most realistic values. In addition, the optimisation of a certain supply chain is usually based on a certain study area resulting in artificial boundaries. This induces the absence of the possibility to import biomass. A possibility to include 'import' in the model is to define the imported product as an extra product.

\section{Conclusion}

To support addressing the obstacles that hamper the development of a strong and sustainable bioenergy sector, a mixed-integer linear programming model, OPTIMASS, is introduced which is developed to tackle strategic and tactical decisions within all kinds of biomass-based supply chains considering the interrelated decisions within the chain, the complex hierarchy in the decision making and the role of each actor within the chain. OPTIMASS can select the optimal location, technology and capacity of operation facilities in combination with the optimal technology to harvest and collect the product. Simultaneously, the optimal allocation of feedstock, intermediates and by-products from biomass production sites to the operation facilities and between operation facilities is determined.

The scenario and sensitivity analyses indicate that OPTIMASS behaves in an expected manner while testing different situations or questions. The main drivers in the decision making process are the transport distances and the requirements at the conversion facility. These requirements impose the need to include changes in biomass characteristics due to harvest and pre-treatment operations. However, also changes in the availability of biomass and in energy demand result in totally different optimal supply chains. This makes clear that the supply chain is very complex, highlighting the need for a comprehensive decision tool. In addition, the scenario analysis illustrates that for relatively small sized problems, it is possible to obtain an optimal solution in a reasonable amount of time. However, a major challenge in the development of OPTIMASS is to limit computation times when the number of operations and facilities increases to represent the real world. Indeed, due to the complexity of the model and the large number of integer variables (a.o. due to the incorporation of pre-treatment operations), computations take a significant amount of time when changing parameter values and adding more operation types and locations.

We believe that OPTIMASS is an inspiring tool to investigate the possible effects of governmental decisions, of considering new biomass material, a new conversion facility, technology changes, etc. Furthermore, OPTIMASS can be used by stakeholders with different perspectives of the same problem. On the one hand, OPTIMASS can be used by stakeholders mostly interested in a macro-analysis defining optimal locations of facilities (e.g. governments, energy producers). On the other hand, OPTIMASS can serve stakeholders interested in the allocation part based on an existing network (e.g. biomass suppliers, owners and operators of storage and conversion facilities). In OPTIMASS, binary variables define whether or not an operation is applied or a facility is opened. This allows users to force certain operations or facilities to be closed or opened by fixing the value of the variable in advance. In this way a user can define the existing facilities or operations available in the supply chain prior to the optimisation. Furthermore, the coupling of the MILP model with a GIS provides the capability to characterise and visualise the problem and/or compute the spatial parameters involved in the problem and to visualise and summarise the optimal result in an interpretative way. The model is connected to a generic and flexible database covering the parameters required in the optimisation model to improve the usability by different stakeholders.

As mentioned in De Meyer et al. (2014), sustainability of supply chains has emerged as a concern to address the potential of supply chains. This implies that sustainable supply chain management needs to integrate consideration of economical, environmental and social objectives. At the moment, OPTIMASS allows the optimisation of these objectives separately. To allow the simultaneous consideration of these multiple, conflicting objectives, the subject of 
ongoing research is the extension of OPTIMASS to a multi-objective MILP by including compromise programming and goal programming techniques. An other subject of ongoing research is the incorporation of time in OPTIMASS. This will improve OPTIMASS to tackle tactical (weekly/monthly) decisions because multiple time periods are considered in the optimisation. This makes it possible to include the seasonal availability of biomass and the conflicting seasonal energy demand in contrast with the constant feeding requirement of the conversion facilities. This will make the need for storage facilities in the biomass supply chain more clear. In this context, the temporal cyclicity in the production of biomass must be considered to determine the optimal moment to harvest. This issue relates to the growth cycle of most biomass types implying that mowing today affects the availability and composition of tomorrow's biomass. In this context, changes in biomass characteristics will be defined as a function of time in comparison to the current model in which the specific characteristics of the different product types are fixed parameters. To test the applicability of OPTIMASS to different kinds of supply chains, the model is being applied to optimise a sludge processing chain in Belgium, the supply of organic waste to composting facilities in Belgium, the supply of poplar to paper mills in Belgium and the use of Jatropha for conversion to bio-oil and biodiesel in Mali. Of course, OPTIMASS is a deterministic model ignoring the uncertainties due to weather conditions, technology uncertainty, and unexpected disruptions caused by natural and human-made factors, etc. However, a thorough sensitivity analysis of these influencing factors already gives insight in the induced changes in the supply chain.

\section{Acknowledgements}

This research is funded by funded by a Ph.D. grant of the Agency for Innovation by Science and Technology (IWT) in Flanders, Belgium. Special thanks goes to Joana Almeida for the help in data gathering and the input in the interpretation of the net energy ratio. Finally, the authors would like to thank the referees of EJOR for the valuable comments and suggestions.

\section{References}

An, H., Wilhelm, W. E., Searcy, S. W., Jul. 2011. Biofuel and petroleum-based fuel supply chain research: A literature review. Biomass and Bioenergy 35 (9), 3763-3774.

Awudu, I., Zhang, J., Feb. 2012. Uncertainties and sustainability concepts in biofuel supply chain management: A review. Renewable and Sustainable Energy Reviews 16 (2), 1359-1368.

Baños, R., Manzano-Agugliaro, F., Montoya, F., Gil, C., Alcayde, a., Gómez, J., May 2011. Optimization methods applied to renewable and sustainable energy: A review. Renewable and Sustainable Energy Reviews 15 (4), 1753-1766.

Bervoets, K., 2008. Nieuwe perspectieven voor beheerresten (New perspectives for management residues). Tech. Rep. april, Natuurpunt ism Vlaamse Overheid.

Bjerg, J., Aden, R., Ogando, J. A., Arrieta, J., Hahlbrock, A., Holmquist, L., Kellberg, C., Kip, W. N., Koch, J., Langnickel, U., Nielsen, C., Rising, A., Rizkova, M., Rookmaaker, J., Ryckmans, Y., Ryymin, R., Shier, C., Sochr, D., Tatar, T., Tolley, A., 2011. Biomass 2020: Opportunities, Challenges and Solutions. Tech. rep., EURELECTRIC Renewables Action Plan (RESAP).

Braekevelt, A., Schelfhout, K., 2013. Inventarisatie biomassa 2011-2012 (biomass inventory 2011-2012). Tech. rep., OVAM, Mechelen.

Caron, G., Kuiper, L., van den Broek, R., 2003. Landschapsstroom - Energetische benutting van biomassa uit natuurterreinen (Landscape stream Energetic utilisation of biomass from natural areas).

Council of Supply Chain Management Professionals, 2012. CSCMP Supply Chain Management Definitions.

D’Amours, S., Ro, M., Weintraub, A., 2008. Using Operational Research for Supply Chain Planning in the Forest Products Industry. Information Systems and Operational Research 46 (4), 265-281.

De Meyer, A., Almeida, J., Achten, W., Muys, B., Cattrysse, D., Van Orshoven, J., 2013a. Incorporating life cycle impact assessment in mathematical model to optimize strategic decisions in biomass-for-bioenergy supply chains. In: Proceedings from the LCA XIII International Conference 'Fulfilling LCA's Promise', October 1-3, 2013, Orlando, FL, United states. pp. 24-33.

De Meyer, A., Cattrysse, D., Rasinmäki, J., Van Orshoven, J., 2014. Methods to optimise the design and management of biomass-for-bioenergy supply chains: A review. Renewable and Sustainable Energy Reviews 31, 657-670.

De Meyer, A., Cattrysse, D., Snoeck, M., Van Orshoven, J., 2012. Generic data model to represent the biomass-to-bioenergy supply chain logistics. In: International Conference on Agricultural Engineering (CIGR-Ageng2012). Valencia, Spain, p. C0156.

De Meyer, A., Ottevaere, C., Cattrysse, D., Van Orshoven, J., 2015. Towards sustainable biomass-for-bioenergy supply chains by trading off between multiple objectives. In: Proceedings from the Young Researchers' Conference on the World Sustainable Energy Days 2015 'Energy efficiency and Biomass', February 25-26, 2015, Wels, Austria.

De Meyer, A., Van Orshoven, J., Cattrysse, D., 2013b. Conceptual decision support system to optimise strategic decisions in biomass-for-bioenergy supply chains. In: Bijdragen voor Vervoerslogistieke Werkdagen, November 28-29, 2013, Venlo, The Netherlands.

Departement Leefmilieu, Natuur en Energie, V. O., 2006. Vademecum Bermmaaisel. Beperkingen en verwerking van bermmaaisel (Vademecum Verge clippings. Limitations and processing of verge clippings). Druk in de Weer, Brussel. 
Departement Leefmilieu, Natuur en Energie, V. O., 2011. Leidraad Natuurtechniek, Ecologisch bermbeheer (Guideline Nature Technology, Ecological verge management). Departement Leefmilieu, Natuur en Energie, Vlaamse Overheid, Brussels.

Ecoinvent Centre, 2007. ecoinvent data v2.0. ecoinvent reports No. 1-25. Tech. rep., Swiss Centre for Life Cycle Inventories, Dübendorf, Switzerland.

URL www. ecoinvent.org

European Parliament \& Council, 2009. Directive 2009/28/ec of the european parliament and of the council of 23 april 2009 on the promotion of the use of energy from renewable sources and amending and subsequently repealing directives 2001/77/ec and 2003/30/ec.

Fröhling, M., Schwaderer, F., Bartusch, H., Rentz, O., 2010. Integrated planning of transportation and recycling for multiple plants on process simulation. European Journal of Operational Research 207, 958-970.

Gold, S., Seuring, S., Jan. 2011. Supply chain and logistics issues of bio-energy production. Journal of Cleaner Production 19 (1), $32-42$.

Hakuvainen, J., Uusitalo, V., Niskanen, A., Kapustina, V., Horttainainen, M., 2014. Evaluation of methods for estimating energy performance of biogas production. Renewable energy 66, 232-240.

Helbig, S., Kstermann, B., Hlsbergen, K.-J., 2008. Energy balance of different organic biogas farming systems. In: 16th IFOAM Organic World Congress, Modena, Italy, 16-20 June 2008. Modena, Italy, p. 12652.

Iakovou, E., Karagiannidis, A., Vlachos, D., Toka, A., Malamakis, A., 2010. Waste biomass-to-energy supply chain management: a critical synthesis. Waste management 30 (10), 1860-70.

Instituut voor Natuurbehoud, 2001. Biologische waarderingskaart van het vlaamse gewest. geïntegreerde versie van de recentst beschikbare karteringen (56\% bwk, versie 2 en $44 \%$ bwk, versie 1) (biological value map of flanders. integrated version of the most recent surveys (56\% bvm, version 2 and $44 \%$ bvm, version 1$)$ ).

International Energy Administration, 2011. Annual Energy Outlook 2011 with Projections to 2035. Tech. rep., International Energy Administration. Inverde, 2012. Graskracht, Eindrapport (Power of grass, Final report). Inverde, Brussel.

Klose, A., Drexl, A., 2005. Facility location models for distribution system design. European Journal of Operational Research 162 (1), 4-29.

Kuiper, L., Caron, G., Jan. 2003. Energetische benutting van biomassa uit natuurterreinen (Energetic unitilisation of biomass from natural areas). Vakblad Natuurbeheer (1), 3-6.

Lauven, L.-P., 2014. An optimization approach to bioenergy setup planning. Biomass and Bioenergy 70, 440-451.

Mafakheri, F., Nasiri, F., 2014. Modelling of biomass-to-energy supply chain operations: Applications, challenges and research directions. Energy Policy 67, 116-126.

Melkote, S., Daskin, M., 2001. Capacitated facility location/network design problems. European Journal of Operational Research 129 , $481-495$.

Melo, M., Nickel, S., Saldanha-da Gama, F., 2006. Dynamic multi-commodity capacitated facility location: A mathematical modeling framework for strategic supply chain planning. Computers \& Operations Research 33, 181-208.

Melo, M., Nickel, S., Saldanha-da Gama, F., Jul. 2009. Facility location and supply chain management A review. European Journal of Operational Research 196 (2), 401-412.

MIRA, 2011. Milieurapport vlaanderen, achtergronddocument 2010,sector huishoudens (flanders environment report, background document 2010, sector households). Tech. rep., Maene S., Vlaamse Milieumaatschappij.

Papapostolou, C., Kondili, E., Kaldellis, J. K., 2011. Development and implementation of an optimisation model for biofuels supply chain. Energy 36, 6019-6026.

Rahmaniani, R., Ghaderi, A., 2013. A combined facility location and network design problem with multi-type of capacitated links. Applied Mathematical Modelling 37, 6400-6414.

Rentizelas, A. A., Tolis, A. J., Tatsiopoulos, I. P., 2009. Logistics issues of biomass: The storage problem and the multi-biomass supply chain. Renewable and Sustainable Energy Reviews 13 (4), 887-894.

Sahin, G., Sural, H., 2007. A review of hierarchical facility location models. Computers \& Operations Research 34, $2310-2331$.

Shabani, N., Akhtari, S., Sowlati, T., 1998. Value chain optimization of forest biomass for bioenergy production: A review. Renewable and Sustainable Energy Reviews 28, 299-311.

Sharma, B., Ingalls, R., Jones, C., Khanchi, A., 2013. Biomass supply chain design and analysis: Basis, overview, modelling, challenges, and future. Renewable and Sustainable Energy Reviews 24, 608-627.

Shrivasta, S., 2007. Green-supply management: a state-of-the-art literature review. International Journal of Management Reviews 9, 53-80.

Snyder, L., 2006. Facility location under uncertainty: A review. IIE Transactions 38, 537-554.

Tilman, D., Hill, J., Lehman, C., 2006. Carbon-negative biofuels from low-input high-diversity grassland biomass. Science 314, 1598-1600.

Uellendahl, H., Wang, G., Møller, H., Jørgensen, U., Skiadas, I., Gavala, H. N., Ahring, B. K., 2008. Energy balance and cost-benefit analysis of biogas production from perennial energy crops pretreated by wet oxidation. Water science and technology 58, $1841-1847$.

Uhlemair, H., Karschin, I., Geldermann, J., 2014. Optimizing the production and distribution system of bioenergy villages. International Journal Production Economics 147, 67-72.

Van Dael, M., Van Passel, S., Pelkmans, L., Guisson, R., Reumermann, P., Marquez Luzardo, N., Witters, N., Broezee, J., 2013. A techno-economic evaluation of a biomass energy conversion park. Applied energy 104, 611-622.

Van Meerbeek, K., Van Beek, J., Bellings, L., Aertsen, W., Muys, B., Hermy, B., 2014. Quantification and prediction of biomass yield of temperate low-input high-diversity ecosystems. BioEnergy Research.

Velázquez-Martí, B., Fernández-González, E., López-Cortés, I., Salazar-Hernández, D., 2011. Quantification of the residual biomass obtained from pruning of trees in mediterranean almond groves. Renewable energy 36, 621-626.

VLACO, 2011. Data - Overzicht vergunde capaciteit 2011 (.xls) (Data - Overview of licensed capacity 2011 (.xls)).

Walther, G., Schatka, A., Spengler, T., 2012. Design of regional production networks for second generation synthetic bio-fuel - A case study in Northern Germany. European Journal of Operational Research 218, 280-292.

Wee, H.-M., Yang, W.-H., Chou, C.-W., Padilan, M. V., Oct. 2012. Renewable energy supply chains, performance, application barriers, and strategies for further development. Renewable and Sustainable Energy Reviews 16 (8), 5451-5465. 